\title{
1 Annelid brain and nerve cord in siboglinid Riftia pachyptila
}

2

3

4 Nadezhda N. Rimskaya-Korsakova ${ }^{1 *}$, Sergey V. Galkin², Vladimir V. Malakhov ${ }^{1,3}$

7 1Department of Invertebrate Zoology, Faculty of Biology, Lomonosov Moscow State

8 University, Moscow, Russia

9 2Laboratory of Ocean Benthic Fauna, Shirshov Institute of Oceanology of the Russian

10 Academy of Science, Moscow, Russia

$11 \quad{ }^{3}$ Far Eastern Federal University, Vladivostok, Russia

12

13

$14{ }^{*}$ Corresponding author

15 E-mail: nadezdarkorsakova@gmail.com (NNRK)

16 


\section{Abstract}

18 Vestimentifera is a peculiar group of marine gutless siboglinids which has uncertain

19 position in annelid tree. The detailed study of the fragmentary explored central nervous system of vestimentiferans and other siboglinids is requested to trace the evolution of the siboglinid group. Among all siboglinids the vestimentiferans preserve the gut rudiment what makes them a key group to homologize main cerebral structures with the ones of typical annelids, such as supra- and subesophageal commissures, cirsumesophageal connectives etc. Histologically we revealed main annelid brain structures in the compact large brain of Riftia pachyptila: circumesophageal connectives (longitudinal nerve tracts) and commissures (dorsal, supra- and subenteral commissures). Innervation of tentacles makes them homologous to peristomial palps of the rest annelids. The single nerve cord is represented by paired intraepidermal longitudinal strands associated with the ventral ciliary field in vestimentum and bearing giant axons originating from at least four pairs of perikarya. The absence of regularly positioned ganglia and lateral nerves in the nerve cord in vestimentum and trunk and presence of them in the opisthosome segments. Among siboglinids, the vestimentiferans distinguished by a large and significatly differentiated brain which is reflection of the high development of the palp apparatus. Osedax, frenulates and Sclerolinum have less developped brain. Frenulates and Sclerolinum have good ganglionization in the opisthosome, which probably indicates its high mobility.

37 Comparative neuroanatomical analysis of the siboglinids and annelid sister clades allows us to hypothesize that the last common ancestor of siboglinids might had brain with a dorsal commissure giving rise neurite bundles to palps and paired ventral nerve cord. 


\section{Introduction}

43 Vestimentifera is a peculiar group of marine gutless annelids inhabiting mainly areas of hydrothermal vents and hydrocarbon seeps [1-3]. The first anatomical details of the nervous system of Vestimentifera was made in the description of the first discovered vestimentiferan Lamellibrachia barhami [4]. Later on, nervous system was studied in $L$. luymesi [5,6], Riftia pachyptila [7-9], Ridgeia piscesae [10], Oasisia alvinae [11], L. satsuma [12]. By means of light microscopy and histology it was shown the presence of the ventral nerve cords and positions of perikariya and neuropile in brain of larval $[13,14]$ and adult vestimentiferans $[6,9-12,15]$. Electron microscopical studies revealed presence of the sensory cells and glial cells structuring neuropile, and form a myelin sheath around the giant axons [9]. In adult vestimentiferans the brain occupies an unusual for annelids antero-ventral position. Jones and Gardiner [13] found that in juveniles the rudiment of the brain is laid in the base on the dorsal side of the oral siphon. After the reduction of the oral siphon, the brain rudiment shifts to the anteroventral position. Jones and Gardiner [8] suggested that the brain of vestimentiferans is a result of the fusion of the supra- and subesophageal ganglia and the circumesophageal connectives. Based on the fact that a coelomic channel passes through the brain in which the rudimentary intestine remains in young individuals, this assumption seems very likely. However, it needs to be confirmed by a more detailed comparison of the intracerebral structures of vestimentiferans and more typical annelids.

Vestimentiferan tubeworms together with Frenulata [4], Sclerolinum [16] and Osedax [17] refer to annelid group Siboglinidae [18]. The nervous system of the vestimentiferans and the rest siboglinids was studied by various methods at the different levels of detalization what makes them difficult to compare. The architecture of frenulates' central nervous system is known based on histological and histochemical 
Siboglinum caulleryi, S. fiordicum and Nereilinum murmanicum, and derived ones as Polybrachia annulata, Spirobrachia grandis [18-24]. Electron microscopy revealed presence of glial and sensory elements in epidermis of frenulates [25]. Structure of central nervous system of females and dwarf males of Osedax is described by means of immunohistochemistry combined with confocal microscopy that revealed numerous commissures and connectives in the brain and trunk nervous system $[26,27]$. Semi-thin sectioning and light microscopy revealed in brain of Sclerolinum contortum the layers of apical perikarya and basal neuropile [28]. Precise ultrastructural neural studies on

Osedax and Sclerolinum were not yet made. Thus, the degree of anatomical study of the organization of the nervous system of vestimentiferans and other siboglinids remains fragmentary and insufficient to make meaningful comparisons with the nervous system of annelids, to which siboglinids are close, according to phylogenetic data [2934]. Detailed neural reconstructions by comparable methods of siboglinids are higly requested to identify key features and trace their neural evolution. system remains controversial. Various annelid sister groups have been proposed, e.g. Oweniidae [35,36], Sabellidae [31,37], Cirratuliformia [38,39], or Clitellata $[40,41]$. Nervous system of the listed annelids is described by various authors [42-52], but there is still no attempts to reveal if there is any neural similarities among siboglinids and proposed sister groups of annelids.

Among all siboglinids the juvenile of vestimentiferans preserve the gut rudiment, so it is the key group to homologize the supra- and subesophageal brain parts of ventral brain

90 of siboglinids with the typical annelid brains. Moreover, vestimentiferans are distinguished by their enormous sizes (Riftia reaches $1,5 \mathrm{~m}$ in length) what makes their histological studies very informative for 3D reconstructions. The main goal of the current work is to reconstruct organization of the central nervous system of vestimentiferan 
94 tubeworm Riftia pachyptila with special accent to its brain structure. This data is

95 necessary for comparison of neuroanatomy of vestimentiferan tubeworms and sister

96 groups of annelids to find the possible ancestor features in the nervous system of 97 siboglinids.

98

99 Materials and Methods

\section{Collection and Fixation}

101 Five specimens of Riftia pachyptila Jones, 1981 [7] were collected at different latitudes 102 of the East Pacific Rise (EPR), including the Guaymas Basin, Gulf of California, by the

103 Pisces manned submersible during the 12th cruise of RV Akademik Mstislav Keldysh in 1041986 and by Mir-1 \& 2 manned submersibles during its 49th cruises in 2003. Lengths of 105 examined specimens are from 8 to $808 \mathrm{~mm}$. In Table 1 there is the data on collection 106 sites and sexes of specimens.

107 Table 1. The studied specimens collected during cruises of the RV Akademik Mstislav Keldysh (AMK).

\begin{tabular}{|c|c|c|c|c|c|}
\hline & \multicolumn{2}{|c|}{ specimens } & \multicolumn{3}{|c|}{ collection sites } \\
\hline$\#$ & $\operatorname{sex}$ & $\begin{array}{l}\text { length, } \\
\mathrm{mm}\end{array}$ & name \& coordinates & depth, $\mathrm{m}$ & $\begin{array}{l}\text { \# station, ROV, } \\
\text { year }\end{array}$ \\
\hline 1 & juvenile & 8 & $\begin{array}{l}9^{\circ} \mathrm{N} \text { EPR: } \\
09^{\circ} 50,53^{\prime} \mathrm{N}, 104^{\circ} 17,51^{\prime} \mathrm{W}\end{array}$ & 2552 & $\begin{array}{l}\text { АМК-4668, Mir-1, } \\
2003\end{array}$ \\
\hline 2 & female & 16 & $\begin{array}{l}\text { Guaymas Basin: } \\
27^{\circ} 02,45^{\prime} \mathrm{N}, 111^{\circ} 22,80^{\prime} \mathrm{W}\end{array}$ & 1990 & $\begin{array}{l}\text { AMK-1519, Pisces- } \\
\text { VII, } 1986\end{array}$ \\
\hline 3 & female & 34 & $\begin{array}{l}9^{\circ} \mathrm{N} \text { EPR: } \\
09^{\circ} 50,52^{\prime} \mathrm{N}, 104^{\circ} 17,52^{\prime} \mathrm{W}\end{array}$ & 2524 & $\begin{array}{l}\text { AMK - 4623, Mir-1, } \\
2003\end{array}$ \\
\hline 4 & male & 79 & $\begin{array}{l}9^{\circ} \mathrm{N} \text { EPR: } \\
09^{\circ} 50,52^{\prime} \mathrm{N}, 104^{\circ} 17,52^{\prime} \mathrm{W}\end{array}$ & 2524 & $\begin{array}{l}\text { АMК-4623, Mir-1, } \\
2003\end{array}$ \\
\hline 5 & female & 808 & $\begin{array}{l}\text { Guaymas Basin: } \\
27^{\circ} 00,47^{\prime} \mathrm{N}, 111^{\circ} 24,57^{\prime} \mathrm{W}\end{array}$ & 2001 & $\begin{array}{l}\text { AMK-4714, Mir-2, } \\
2003\end{array}$ \\
\hline
\end{tabular}




\section{Histology \& LM photography}

Four animals used for anatomical analysis were fixed in Bouin's solution and

112 stored in $70 \%$ ethanol. The material was processed by the standard histological

113 procedure, including dehydration in alcohols and embedding in paraffin, paraplast, or

114 histowax. Transverse sections (5 and $7 \mu \mathrm{m})$ were produced with a Leica RM 2125

115 microtome (Leica Microsystems, Wetzlar, Germany), stained with Caracci hematoxylin,

116 and examined under a Zeiss Axioplan2 microscope equipped with AxioCam HRm

117 camera (Carl Zeiss Microscopy, LLC, United States) as well as Leica DM5000 B

118 equipped with Leica DFC425 C camera. Microscopic images optimized for contrast and

119 level in Adobe Photoshop 7.0 (Adobe Systems, San Jose, CA, USA). Drawings were

120 performed with Adobe Illustrator CC 2014. For visualization of the anastomosing

121 neurites in the trunk epidermis a specimen of $808 \mathrm{~mm}$ was pictured by Canon Power

122 Shot S90 camera.

\section{D modeling}

Arrangements of neurite bundles in the brain and the anteriormost ventral nerve cord were visualized with the software 3D-DOCTOR 3.5.040724 (Able Software

127 Corporation of Lexington, USA). Alignment was performed in the same software with comparing the sections of adjacent planes. Image seria of 77 cross sections of the 78 mm specimen was used for modeling of the brain organization. 19 objects were traced

130 inside brain, including boundary of the brain. Photos are saved in JPEG format with a 131 resolution of $3900 \times 3090$ pixels and 8 bits / pixel. The field of view is $2812.00 \mu m$, the 132 parameters of the voxels of the images are $0.721026 \times 0.721026 \times 15 \mu \mathrm{m} 3$. On the 133 basis of the outlined boundaries three-dimensional models were obtained. The 134 smoothing tool used for natural perception of the surface of objects. Interactive features 135 as well as transparency filter, different colours and lighting effects applied to show 
136 complex and hidden objects. Three-dimensional images under appropriate angles were

137 processed in Adobe Photoshop 7.0 (Adobe Systems, San Jose, CA, USA).

\section{Results}

\section{Gross anatomy of nervous system}

141 Riftia's central nervous system is composed of a ventral brain and ventral nerve cord

$142(B, V N C$, Figs 1A, 2A, 3A, 4A).

144 Fig 1 Anterior part of the ventral nerve cord of Riftia pachyptila.

145 A - scheme of the central nervous system which main elements are in grey, and giant 146 axons are in light grey. The frame indicates the area corresponding to histological cross

147 (B-D) and parasagittal (E) sections. Dotted lines show the region borders. B 148 posteriormost brain; elements of the ventral nerve cord projecting into the brain. C 149 ventral nerve cord (VNC) just posterior to the brain. D - longitudinal nerves in the 150 transition of the ventral nerve cord and brain. $\mathrm{E}$ - the intraepidermal ventral nerve cord 151 (VNC). B - brain, CNC - commissural neurite bundles of the VNC, cpnc - central 152 perikarya of the $V N C, C U$ - cuticle, ECM - extracellular matrix, EP - epidermis, EXP 153 epidermal cell processes, $G A$ - giant axons, $G C$ - enteral coelom, $L N$ - circular neurite 154 bundles, Ipnc - lateral perikarya of the VNC, IVtp - ventrolateral perikarya of the 155 tripartite ventral aggregation, $N E$ - neuropile of the lateral brain lobes, nep - peripheral 156 perikarya of the lateral brain lobes, $O B$ - obturaculum, $O B C$ - obturacular coelom, $O P$ 157 opisthosome, $p m p$ - posterior median perikarya aggregation, $P N C$ - paired strands of 158 the VNC surrounding the ventral ciliary field, vvtp - ventral perikarya of the tripartite 159 ventral aggregation, TR - trunk, VNC - ventral nerve cord, VT - vestimentum, VWF 160 collar of the vestimental wings, VWN - neurite bundle of the VW. 


\section{$161 \quad$ Fig 2 The ventral nerve cord in vestimentum of Riftia.}

$162 \mathrm{~A}$ - scheme of the central nervous system which main elements are in grey, and giant axons are in light grey. The frame indicates the area corresponding to histological cross sections (B-E). B - ventral nerve cord just anteriorly to the ventral ciliary field. C - ventral ciliary field $(C F)$ surrounded by the paired strands of the ventral nerve cord $(P N C)$; line shows the border of the ciliary field, braces show the strands of the ventral nerve cord. D - precise view of the left strand of the ventral nerve cord, commissural neurite bundles connecting the paired strands are seen $(C N C)$. E - lateral circular neurite bundles $(L N)$ in the epidermis. $B$ - brain, $B V$ - blood vessels, $C N C$ - commissural neurite bundles of the VNC, CM - circular musculature, CF - ventral ciliary field, CIL - cilia, cpnc - central perikarya of the VNC, CU - cuticle, ECM - extracellular matrix, ega - cells coating the $G A, E P$ - epidermis, $G A$ - giant axons, $L N$ - circular neurite bundles, Ipnc - lateral perikarya of the VNC, NNC - neuropile of the VNC, $O B$ - obturaculum, $O P$ opisthosome, PNC - paired strands of the VNC surrounding the CF, TR - trunk, VNC ventral nerve cord, $V T$ - vestimentum.

\section{Fig 3 The ventral nerve cord in trunk and opisthosome of Riftia.}

177 A - scheme of the central nervous system which main elements are in grey, and giant axons are in light grey. The frame indicates the area corresponding to histological sections (B-D, F, G) and light miscroscopical image (E). B - the ventral nerve cord (VNC) structure in the anterior trunk. C, D - VNC structure in the midtrunk and posterior

181 trunk, respectively; note the reduction of the giant axon diameter. E - lateral neurite 182 bundles branching and making anastomoses in the trunk epidermis. F-E - VNC in the 183 middle and posterior part of the opisthosome. Arrows in (F) show the cuticular folds 184 between cell borders. ECM - extracellular matrix, BV - blood vessels, $C M$ - circular muscles, $D$ - dissepiments, ega - cells coating the $G A, E P$ - epidermis, EXP -

186 epidermal cell processes, $G A$ - giant axons, $F M$ - featherlike longitudinal muscles, $L G$ 
187 - longitudinal lateral grooves, $L M$ - longitudinal muscles, $L N$ - circular neurite bundles,

188 Ipnc - lateral perikarya of the VNC, ME -mesenterium, NNC - neuropile of the VNC,

189 OP - opisthosome, $P A$ - cuticular plaque papillae, $p l$ - large perikarya, $p s$ - small

190 perikarya, TR - trunk, VNC - ventral nerve cord.

191 Fig 4 Brain of juvenile Riftia with a gut rudiment.

192 A - scheme of the sagittal section of the vestimentiferan brain which consists of

193 supraesophageal and subesophageal ganglia. B - parasagittal section of the $8 \mathrm{~mm}$ long

194 juvenile, the gut rudiment passes through the vestimentiferan brain. amp - anterior

195 median aggregation of perikarya, CUP - cuticle schild, DC - dorsal commissure, DLN -

196 dorsal area of the longitudinal bundles, ET - excretory tree, $G$ - gut lumen, GC -

197 enteral coelom, $H$ - heart, $L N C$ - lateral connectives, nep - peripheral perikarya of the

198 lateral brain lobes, OBC - obturacular coelom, OBL - obturacular lobes, OBN -

199 obturacular neurite bundles, OBV - obturacular blood vessels, pmp - posterior median

200 perikarya aggregation, SBC - subenteral commissure, SLN - supraenteral longitudinal

201 neurite bundles, SPC - supraenteral commissure, SV - sinus valvatus, vtp - tripartite

202 ventral aggregation of perikarya, VNC - ventral nerve cord, VWF - collar of the 203 vestimental wings.

205 Ventral brain lies in the anteriormost vestimentum (Figs 1A, 4A-B). There are two brain 206 lobes forming heart-like shape on transverse sections (Figs 5-7, S1-S3 Figs). Dorsal 207 furrow between the brain lobes encloses the obturacules' bases (OBL, Figs 4A, 5-6, 208 S1 Fig). Posteriorly the excretory tree is adjacent to the brain ( $E T$, Fig 4B). The whole 209 brain lies inside the epithelium, and there are no basal laminae separating brain from 210 epidermis (EP, Figs 4-7, S1-4). Cuticle schild protects the apical surface of the brain 211 (CUP, Figs 4B, S1-3 Figs). Collar of vestimental wings shelters the ventral brain from 212 outside (VWF, Fig 1B, 4). The $80 \mathrm{~mm}$ long specimen has a brain of $1 \mathrm{~mm}$ in height and 
213 length, $2 \mathrm{~mm}$ in width. Undifferential tentacle lamellae lie on the dorsal and lateral

214 surface of the brain ( $L R$, Figs 5-7, S1-S3A, S5 Figs). Posterior brain has mainly dorsal

215 lamellae (Figs 6-7, S3A Fig), whereas in anterior brain the tentacle lamellae occupy

216 dorsal surface as well as descend to the lateral and ventrolateral surfaces (Figs 5, S1, 217 S2 Figs).

219 Fig 5. Anterior brain organization of Riftia.

220 Scheme of histological cross section based on anterior brain sections of $79 \mathrm{~mm}$ long specimen (see S1 Fig). Level of the section shown at the diagram at the right lower coner. amp - anterior median aggregation of perikarya, $D C$ - dorsal commissure, $D L N$ - dorsal area of the longitudinal bundles, dop - dorsal aggregation of perikarya, EP _ epidermis, GC - enteral coelom, $L N T$ - longitudinal nerve tracts projecting from the $V N C$ into the brain, $L R$ - undifferential tentacle lamellae, $N E$ - neuropile of the lateral brain lobes, nep - peripheral perikarya of the lateral brain lobes, $O B C$ - obturacular coelom, $O B L$ - obturacular lobes, $O B N$ - obturacular neurite bundles, OBV obturacular blood vessels, SLN - supraenteral longitudinal neurite bundles, TEN neurite bundles of tentacles (palps), VSN - vertical supraenteral neurite bundles, vtp -

230 tripartite ventral aggregation of perikarya, vvtp - ventral perikarya of the vtp, $X X L$ - pair

231 of prominent bundles of large longitudinal nerve tracts (part of $L N T$ ).

\section{Fig 6. Middle brain organization of Riftia.}

233 Scheme of cross section based on midbrain histological sections of $79 \mathrm{~mm}$ long 234 specimen (see S2 Figure). Level of the section shown at the diagram at the right lower 235 coner. $D C$ - dorsal commissure, DLN - dorsal area of the longitudinal bundles, dop 236 dorsal aggregation of perikarya, EP - epidermis, $G A$ - giant axons, GC - enteral 237 coelom, ECM - extracellular matrix, $L N C$ - lateral connectives, $L N T$ - longitudinal nerve 238 tracts projecting from the VNC into the brain, $L R$ - undifferential tentacle lamellae, Ivtp - 
239 ventrolateral perikarya of the vtp, NE - neuropile of the lateral brain lobes, nep -

240 peripheral perikarya of the lateral brain lobes, $O B C$ - obturacular coelom, $O B L-$

241 obturacular lobes, OBV - obturacular blood vessels, $p l$ - large perikarya, ps - small

242 perikarya, SBC - subenteral commissure, SPC - supraenteral commissure, TEN -

243 neurite bundles of tentacles (palps), vtp - tripartite ventral aggregation of perikarya, VPN

244 - posterior vertical median bundles.

245 Fig 7. Posterior brain organization of Riftia.

246 Scheme of cross section based on posterior brain histological sections of $79 \mathrm{~mm}$ long

247 specimen (see S3 Figure). Level of the section shown at the diagram at the right lower

248 coner. $D C$ - dorsal commissure, ECM - extracellular matrix, EP - epidermis, GA - giant

249 axons, GC - enteral coelom, $L N T$ - longitudinal nerve tracts projecting from the ventral

250 nerve cord into the brain, $L R$ - undifferential tentacle lamellae, Ivtp - ventrolateral

251 perikarya of the vtp, NE - neuropile of the lateral brain lobes, nep - peripheral perikarya

252 of the lateral brain lobes, $O B C$ - obturacular coelom, OBV - obturacular blood vessels,

$253 \mathrm{pl}$ - large perikarya, pmp - posterior median perikarya aggregation, ps - small

254 perikarya, SBC - subenteral commissure, TEN - neurite bundles of tentacles (palps),

$255 v t p$ - tripartite ventral aggregation of perikarya, vvtp - ventral perikarya of the vtp.

257 Three coelomic channels pass through the brain tissue: pair of obturacular coeloms 258 with blood vessels and unpaired enteral coelom (OBC, GC, Figs 4-7, S6 Fig). In 259 juvenile undivuduals the enteral coelom comprises gut rudiment (G, Fig 4A). In larger 260 specimens the enteral coelom is occupied with mesenchymal cells (Figs 6). In anterior 261 brain the enteral coelom has « $₫$ » shape of transverse profile (Figs 5 ). Oral siphon is 262 preserved in juvenile Riftia having $34 \mathrm{~mm}$ in length, and the intestine rudiment remains 263 in the coelomic channel running through the brain, in individuals having $79 \mathrm{~mm}$ in 264 length. In larger individuals the only coelomic channel remains. 
265 Ventral nerve cord (VNC) connects to the brain via longitudinal neurite bundles (Figs

266 1B-E). Anteriorly to the ventral ciliary field $(C F)$ the VNC splits into a pair of strands

267 (PNC) connected to each other with transverse neurite bundles (Fig 2A-D). The strands

268 surround the ventral ciliary field (Figs $2 \mathrm{~B}-\mathrm{C}$ ). The strands fuse into a single VNC at the

269 border of the vestimentum and trunk and extend along ventral midline till the end of the

270 body (Fig 3A). The width of the prominent VNC can reach up to $1 \mathrm{~mm}$ in a specimen of

$271808 \mathrm{~mm}$ long (Fig 3B). Its width decreases to posterior trunk (Figs 3C-D).

272 The VNC is lying inside the epidermis (Fig. 1E). The epidermal cells have a wide apical

273 part adjacent to cuticle and basal process to the layer of the ECM (Fig. 1C).

274 Apically thick cuticular layer (CU) protects VNC, especially in the anteriormost part (Fig 275 1C). In opisthosome the cuticle protecting VNC makes folds between the apical parts of 276 epidermal cells (arrows, Fig 3F).

\section{Dorsal brain structures}

279 Brain of $R$. pachyptila consists of dorsal and ventral parts divided by position of the enteral coelom (Figs 4-8).

\section{Fig 8. Supra- and subesophageal ganglia in Riftia.}

283 3D models of Riftia brain. A-D - supraesophageal neuronal elements. E-H subesophageal neuronal elements in Riftia brain. View sides shown at the right lower corners of each images. Cube side is $255 \mu \mathrm{m}$. Dashed lines point neural elements under transparent structures. amp - anterior median aggregation of perikarya, DC -

287 dorsal commissure, DLN - dorsal area of the longitudinal bundles, GA - giant axons,

288 gap - giant perikarya, GC - enteral coelom, LNT - longitudinal nerve tracts projecting from the ventral nerve cord into the brain, Ivtp - ventrolateral perikarya of the vtp, NE neuropile of the lateral brain lobes, nep - peripheral perikarya of the lateral brain lobes, 
291 pmp - posterior median perikarya aggregation, SBC - subenteral commissure, SPC -

292 supraenteral commissure, SLN - supraenteral longitudinal neurite bundles, VPN -

293 posterior vertical median bundles, VSN - vertical supraenteral neurite bundles, vtp -

294 tripartite ventral aggregation of perikarya, vvtp - ventral perikarya of the vtp.

296 Most part of the dorsal brain occupied by paired areas of neuropile of the lateral brain 297 lobes $(N E)$ in the thickness of which there are many perikarya (Figs 5-8, S1-S3, S7A-

298 C', S8 Figs). Numerous radial tentacle neurite bundles extend from the neuropile of the 299 lateral brain lobes to the bases of the tentacle lamellae, these are tentacle neurite 300 bundles (TEN, Figs 5-6, S1-S3, S5 Figs). Each lamella represents the thin fold of the 301 epidermis (Figs S5 A-D). Lamellae are closely adjacent to each other, and epidermis of

302 external lamellae wall $(O E P)$ is flattened, epidermis of the internal wall (IEP) is 303 thicker and contain the basiepithelial tentacle neurite bundles (S5A Fig).

304 Neuropiles of right and left brain lobes are connected by thick extended dorsal commissure (DC, Figs 4, 5-7, 8A-C, 9, S1-S3, S7A-H Figs). It lies over the paired

306 obturacular coelomic channels and adjacent to their loops anteriorly (S8F-G Figs).

307 Transverse neurite bundles included in the dorsal commissure are divided into two

308 almost equal parts: anterior and posterior commissures (Figs 9A, B, E, S8F, G Figs).

309 Both dorsal commissures (anterior and posterior) of large specimen are structured in 310 dorso-ventral direction and comprises of several layers of neurite bundles which are

311 visible at the transverse section (up to 5 levels in $79 \mathrm{~mm}$ long specimen, S2A Fig). Up to

312 9-11 ventro-dorsal vertical bundles go through the dorsal commissure clearly visible at 313 sagittal and parasagittal sections (Fig 4A).

315 Fig 9. Longitudinal nerve tracts and main commissures in Riftia brain. 
316 3D models of Riftia brain. A-E - main commissures (dorsal, DC, supra-, SPC, and

317 subesophageal, $S B C)$ and longitudinal nerve tracts (LNT). The latter is homologous to

318 circumesophageal connectives in another annelids' brain. View sides shown at the right

319 lower corners of each images. Cube side is $255 \mu \mathrm{m}$. Dashed lines point neural elements

320 under transparent structures. $D C$ - dorsal commissure, $G A$ - giant axons, $G C$ - enteral

321 coelom, $L N C$ - lateral connectives, $L N T$ - longitudinal nerve tracts projecting from the

322 ventral nerve cord into the brain, $S B C$ - subenteral commissure, SPC - supraenteral

323 commissure, $X X L$ - pair of prominent bundles of large longitudinal nerve tracts (part of

$324 L N T)$.

326 Two pairs of obturacular neurite bundles $(O B N)$ extend from the dorsalmost area of

327 the brain from the anterior dorsal commissure to the bases of obturacular lobes (Figs 5,

328 10A, S1, S9A-F). Each pair of obruracular bundles (left and right) gives rise neurite

329 bundles in the epidermis of inner and outer sides of the obturacular lobes. In that area

330 neurite bundles run vertically, then in the dorsal part of obturacules move in posterior-

331 anterior direction.

332 In the midbrain there is a weak supraenteral commissure (SPC) running over the

333 enteral coelomic channel, but under the obturacular channels (Figs 4A, 9B-D, 10B, C,

334 S3A, S8D-E, S9J, S10B, D Figs). In anterior brain two prominent supraenteral

335 longitudinal neurite bundles $(S L N)$ directs backward from the anteriormost brain and

336 disintegrate into separate small bundles at the level of the supraenteral commissure

337 (compare Figs 5\&6, Figs 8A, S1, S2, S8, S10A, C, D Figs). Supraenteral longitudinal

338 neurite bundles are connected to each other via vertical supraenteral neurite bundles

339 (VSN) which have inverted "Y»-like shape (Figs 5, S2B, S8A-C Figs). Moreover, the

340 vertical bundles join different parts of fibers of an anterior median aggregation of

341 perikarya (amp): vertical fibers connect dorsal and ventral parts of the aggregation, as 
342 well as transverse fibers connect left and right halves of the aggregation (Figs 4, 5, S2,

343 S8 Figs).

345 Fig 10. Histological details in the anterior brain of Riftia.

346 A - obturacular neurite bundles $(O B N)$ connecting with the dorsal commissure $(D C)$. B,

347 C - giant perikarya with clear nuclei in juvenile brain. D - anterior vertical median 348 bundles (VAN) comprising of giant axons (GA). E - posterior vertical median bundles 349 (VPN) with no giant axon. F - giant perikarion degrading in brain of $79 \mathrm{~mm}$ long male. $\mathrm{G}$ 350 - cuticular plate protecting the brain (CUP). ECM - extracellular matrix, CU - cuticle, 351 CUP - cuticle schild, DC - dorsal commissure, $D L N$ - dorsal area of the longitudinal 352 bundles, dop - dorsal aggregation of perikarya, EP - epidermis, GA - giant axons, gap 353 - giant perikarya, $L N T$ - longitudinal nerve tracts projecting from the VNC into the brain,

$354 N E$ - neuropile of the lateral brain lobes, nep - peripheral perikarya of the lateral brain 355 lobes, $O B C$ - obturacular coelom, $O B L$ - obturacular lobes, $O B N$ - obturacular neurite 356 bundles, $O B V$ - obturacular blood vessels, $p /$ - large perikarya, $p s$ - small perikarya, 357 SPC - supraenteral commissure, TEN - neurite bundles of tentacles (palps), vtp 358 tripartite ventral aggregation of perikarya, VPN - posterior vertical median bundles, VAN 359 - anterior vertical median bundles, $X X L$ - pair of prominent bundles of large longitudinal 360 nerve tracts (part of $L N T$ ).

362 On the dorsalmost side of the midbrain (close to ECM layer) there is a pair of dorsal 363 areas of the longitudinal bundles (DLN, Figs $4 A, 5,6,8 A-D, 10 A, S 1, S 2$, S3A, S9A364 C). They start from a dorsal aggregation of perikarya (dop) in the midrain (Figs 5, $36510 \mathrm{~A}, \mathrm{~S} 1, \mathrm{~S} 2 \mathrm{Figs})$ and lie along the dorsal groove of the brain. The dorsal areas of the 366 longitudinal bundles expand widely along the site of the groove untill the place of 367 obturacules enter the brain. 
368 Short anterior vertical median bundles (VAN) pass between the obturacular coeloms

369 in the midbrain (Figs 10B-D, S10 Fig). They extend ventro-dorsally between the 370 supraenteral commissure and the the roots of anterior dorsal commissure. Anterior

371 vertical median bundles comprise of the crossing neurite bundles: the neurite bundles

372 originating from the right side of the supraenteral commissure extend to the left side of

373 the dorsal commissure, and vice versa.

374 Posteriorly to the anterior vertical median bundles there are posterior vertical median 375 bundles (VPN, Figs $6,8 \mathrm{~B}, 10 \mathrm{E}, \mathrm{S} 3 \mathrm{~A}, \mathrm{~S} 10$ Figs). They do not contain any crossing 376 bundles and connect the supraenteral commissure and the posterior dorsal 377 commissure.

378 Periferic perikarya of the lateral brain lobes (nep, Figs 4-7, 8A-D, S1-S3, S5A, S6A,

379 C, E, S7I, J, S9A Figs) are represented by two layers: inner layer of small perikarya, 5 $380 \mu \mathrm{m}(p s)$, and outer layers of big ones ( $p /), 20 \mu \mathrm{m}$ (Fig 7, S3A, S5A Figs). In juvenile 381 specimens having lower number of tentacle lamellae the small perikarya are grouped 382 into distinct lobules which correspond to the tentacle lamellae. In bigger specimens 383 having higher number of tentacle lamellae arrangement of small perikarya are even. In 384 anterior part of the brain the periferic zone of perikarya expands significantly and covers 385 laterally a tripartite ventral aggregation of perikarya (vtp, Figs $5-7$, S1-S3, S7I, J, 386 Figs, more about vtp read below).

387 In the dorsal groove of the anterior brain there is a dorsal aggregation of perikarya 388 (dop) which lies in the inner sides of obturacules entering the brain (Figs 5, 6, 10A, S1, 389 S2, S3A Figs). It contains two layers of perikarya: in contrast to perifiric perikarya there 390 are inner big perikarya and outer small ones (Figs 5, 10A).

391 The anterior median aggregation of perikarya (amp) is the most anterior symmetrical 392 accumulation of big somata (Fig 4, 5, 8A, C, S1, S2, S8 Figs). It is adjacent dosally to 393 the enteral coelomic channel. 


\section{Ventral brain structures}

396 In the ventral brain, under the enteral coelomic channel, there is a main subenteral

397 commissure (SBC, Fig 4, 6, 7, 8E-H, 9, S3, S8D-G Figs) which is a continuation of the

398 transverse neurites in the ventral nerve cord (CNC, Fig. 2B).

399 The most neuropile of the ventral brain is occupied by paired prominent longitudinal 400 nerve tracts (LNT, Figs 1B-D, 6, 7, 8B-D, 9, 10A, S1-S3, S7, S9B-J Figs) which are

401 continuations of nerve fibers from the ventral nerve cord (Figs 1B-D). As the longitudinal

402 nerve tracts come into the brain, each of them lies around three coelomic channels and 403 gradually rises to the dorsal side of the brain (Figs 5-7).

404 In the dorsal brain the tracts contain a pair of large bundles of thick fibers, $6-11 \mu \mathrm{m}$ in 405 diameter of a fiber ( $X X L$, Figs 5, 9A, B, E, 10A-C, F, S2B, S7D, E, G, S9B, C Figs). 406 Anteriorly the prominent bundles fall apart into several smaller bundles which 407 disintegrate in the neuropile of the lateral brain lobes (S7A', B', D, G Figs).

408 Neurites of the neuropile of the lateral brain lobes $(N E)$ originate from the longitudinal 409 nerve tracts (Figs 5-7, 8B-D, S1-S3, S7 Figs).

410 In the anterior dorsal brain, the longitudinal nerve tracts are connected to each other via

411 the dorsal commissures $(D C)$ over the obturacular coeloms (Figs 5, 9, S1, S2, S7A'-H, 412 S9B-C Figs) and via the supraenteral commissure (SPC) under the obturacular coeloms

413 (Figs 6, 9B-D, S3A Fig). In the ventral brain the pair of the longitudinal nerve tracts are

414 binded by subenteral commissure (SBC, Figs 6, 7, 9, S7B', C', G Figs).

415 The ventralmost part of the brain, under the enteral coelom, is occupied with the

416 tripartite ventral aggregation of perikarya (vtp, Figs 4-7, 8E-H, 10G, S1, S2A, S6A-D,

417 S7A-C, I, J, S8D, E Figs) comprising of small and big perikarya (Fig 6). On transverse 418 sections it is divided in three lobes: ventral and two ventrolateral ones ( $v v t p$, Ivtp, Figs 7, 419 S2B, S3, S6 Figs). In the posterior brain lobes enter the brain neuropile significantly 
420 (Figs 6, 7, S3). In anterior brain the unpaired ventral lobe adjoins the ventral side of the

421 enteral coelomic channel (Figs 5, 8F, G, S1, S2, S6D-F Figs). In the posterior brain two

422 groups of big perikarya, posterior median perikarya aggregations ( $p m p)$, extend from

423 the tripartite aggregation forward and lie along the left and right sides of three coelomic 424 channels (Figs 7, 8E-H, S3B, S6F Figs).

\section{Giant perikaria and axons}

427 Giant axons run in the middle and posterior brain parts ( $\mathrm{AA}$, Figs $6,7,8 \mathrm{~B}-\mathrm{H}, 9$, S3, 428 S9G-L, S10B-G Figs). In juvenile and male specimens, we found two pairs of dorsal 429 giant perikarya (gap) lying in the dorsal neuropile of the dorsal commissure and the 430 longitudinal nerve tracts (Figs 10B, C, F). Nuclei as well as nucleoli remain in the giant 431 perikarya of juvenile, but not in male specimen (Figs 10B, C). Axons of the dorsal giant 432 perikarya run ventrally as part of the crossing anterior vertical median bundles (VAN, 433 Figs 10B-D, S10 Fig).

434 3D-modelling of studied juveniles revealed two pairs of lateral branches of giant axons 435 in lateral neuropiles of longitudinal nerve tracts which do not have giant perikarya (S9G, $436 \mathrm{~L}, \mathrm{~S} 10 \mathrm{E}-\mathrm{G}$ Figs). Perhaps in younger specimens they remain. In the posterior brain the 437 giant axons extend inside the longitudinal nerve tracts and continue inside the neuropile 438 of the ventral nerve cord (Figs 9, S9G-J Figs). Transversally the giant axon represents 439 the $20-25 \mu \mathrm{m}$ round profile with light cytoplasm and enveloped by flattened cells with 440 dark nuclei (S3 Fig).

\section{Ventral nerve cord}

443 In vestimentum neuropile of the paired ventral nerve cord (VNC) consists of two lateral

444 longitudinal nerves (LNT, Figs 1B-D) connected via transverse (commissural) neurite 445 bundles (CNC, Figs 1B, D, 2B). Pair of giant axons lies in the central part of VNC (Figs 
446 1A-D). Numerous small perikarya form two lateral and one central accumulations (Ipnc,

447 cpnc, Figs 1C, D) which are continuations of the ventral tripartite aggregation of the

448 ventral brain (vvtp, Figs 1B, C).

449 Around the ventral ciliary field each strand of PNC contains the epidermal cells, basal 450 neuropile, apical perikarya, and single fiber of the giant axon envelopped with the 451 coating cells (ega) (Fig 2D). Most perikarya lie externally to the giant axon in each 452 strand. The ciliary field consists of columnar ciliary epidermal cells (Fig 2C). In their 453 basal parts there are commissural neurite bundles (CNC) which make a net and 454 connect the strands with each other (Figs 2A, B, D).

455 In trunk the VNC has permanent diameter, neuropile has no swellings and separated by 456 the giant axon into two longitudunal strands (Figs 3A-D). The epidermal cells' processes 457 extend to the ECM inside the neuropile (EXP, Fig 3B). The VNC perikarya spread along 458 left and right sides of the giant axon (Figs. 3B-D). There are small $(3,5 \mu \mathrm{m})$ and big (20 $459 \mu \mathrm{m}$ ) perikarya ( $p s, p l$, Fig 3B). Giant axon extends to the border of the trunk and 460 opisthosome (Fig 3D).

461 In opisthosome an arragement of the apical somata and basal neuropile of the VNC is 462 the same as in the rest body (Figs 3F, G). There is no giant axon, all perikarya are 463 small.

\section{Segmental nerve bundles}

466 In the anteriormost vestimentum several thick transverse lateral neurite bundles part

467 off the ventral nerve cord ( $L N$, Fig $1 \mathrm{~A})$. We found 3 pairs of them in $16 \mathrm{~mm}$ long 468 specimen. The first pair, the most prominent one, directing to the anterior collar, is 469 neurites of vestimental wings (VWN, Figs 1A, B). At the level of the ciliary field, many 470 irregular bundles part off the lateral neuropile of the VNC strands and extend into the 471 epidermis of the vestimental wings (Figs 2A, E). Transverse neurite bundles come off 
472 the single VNC in the trunk. They intensively branch and make anastomoses (Fig 3E).

473 In a $79 \mathrm{~mm}$ long specimen, lateral bundles part each $100 \mu \mathrm{m}$ off the cord, thus there are 474 350-360 pairs of bundles in a trunk. In each opisthosomal segment a pair of lateral 475 bundles leaves the neuropile of the VNC (Fig 3A, compare F\&G).

\section{Discussion}

\section{Ventral nerve cord in Vestimentifera}

479 To date described species of vestimentiferans have uniform structure of the ventral 480 nerve cord, except the length of giant axons and organization of perikarya aggregations 481 in trunk $[7,10-12,15,53,54]$. The ventral nerve cord in Ridgeia piscesae and 482 Lamellibrachia satsuma comprises of central neuropile and two lateral strands of 483 perikarya, thus showing somewhat paired structure $[10,12]$, whereas in Riftia (present 484 study) and Oasisia alvinae there are single layers of apical perikarya and basal neuropile [11]. Also, in O. alvinae median groove was found to run along the midline of the ventral nerve cord in opisthosome [11].

487 Pair of giant axons extended from the pair of giant perikarya was found in 488 vestimentiferans Ridgeia, Riftia, Oasisia, Lamellibrachia $[5,10,11,13]$. Giant axons 489 terminate at different levels in trunk nerve cord: in L. luymesi, giant axons terminate in 490 the anterior part of the trunk segment [53], in L. barhami extend a little further back [55], 491 in R. piscesae, O. alvinae and Riftia they extend up to the border between trunk and the 492 first opistosome segment [10,11]. Earlier a pair of giant perikarya was found to be 493 retained in juveniles of $R$. piscesae and $O$. alvinae in the mid-dorsal part of the brain $494[10,11,13,15]$. We found two pairs of giant neurons in juveniles in the dorsal commissure of Riftia (Fig $10 \mathrm{~B}, \mathrm{C}$ ). Besides, the lateral branches of giant axons (S10E496 G Figs) indicate the possible presence in earlier stages two pairs of giant perikarya in 
497 the lateral areas of the neuropile. Thus, each giant fiber in Riftia is a product of the

498 fusion of at least four pairs of axons.

\section{Ventral nerve cord in Siboglinidae}

501 Siboglinids have intraepidermal ventral nerve cord along which most of perikarya evenly

502 dispersed $[9,11,12,19,20,22,23,26-28]$. All siboglinids have paired structure of the

503 ventral nerve cord. First, the ventral nerve cord of vestimentiefrans and frenulates have

504 paired structure in vestimentum and forepart, respectively. Second, there is a pair of

505 giant axons in vestimentiferans and large frenulates. Third, in frenulates,

506 vestimentiferans and Sclerolinum the ventral cord bifurcates into two strands around the

507 ventral ciliated field. In female O. priapus, the only Osedax species with the ventral

508 ciliary field, pair of the ventral cords adjoins the ciliary field. Fourth, in Osedax species

509 (females and males) there is an obvious pair of widely separated strands of the ventral

510 nerve cord in trunk $[9,19,20,22,26-28]$.

511 The ventral ciliary field which is unique stucture conserved in all adult siboglinids lies in

512 the anterior worm part: in trunk of frenulates, in vestimentum of vestimentiferans,

513 forepart of Sclerolinum and anterior trunk of female O. priapus $[9,22,27,28]$. Although

514 the ciliary field in frenulates and both vestimentiferans and Sclerolinum lies in different

515 regions, in all cases it originates from the larval neurothroch. In developing larvae of

516 frenulate Siboglinum fiordicum the anterior part of neurotroch extended to the future

517 forepart, whereas posterior part of neurotroch extended to the future trunk. In $S$.

518 fiordicum only posterior part of neurotroch remains in the in trunk of adults $[56,57]$.

519 Whereas in adult vestimentiferans it is in vestimentum corresponded to the frenulate

520 forepart $[9,27,58]$. We assume that in adult frenulates and vestimentiferans different

521 parts of the neurotroch remains, possibly due to different life modes of the larvae. 
522 Vestimentiferan larvae swim long time in the water, whereas in frenulates it settles and

523 simultaneously goes through metamorphosis.

524 Perikarya do not form accumulations along the most length of the ventral nerve cord,

525 i.e. in forepart/vestimentum and trunk, but their number increases in the region of 526 annular chaetae, as in frenulate Lamellisabella zachsi $[19,20]$ and in short opisthosomal 527 segments of frenulate Siboglinum fiordicum perikarya form ganglia $[21,22]$. In contrast 528 to vestimentiferans' anchoring opisthosome, the frenulates' opisthosome is designed to 529 protrude out of the posterior tube opening and dig into the sediment [22]. Due to the 530 high mobility, in the frenulate opisthosome the nerve cords form three strands with pair 531 of ganglia in each segment in Siboglinum fiordicum $[21,59]$.

532 Giant axons in vestimentiferans Ridgeia, Riftia, Oasisia $[10,11,13]$ were found to extend 533 up to the posterior end of the the trunk. In large frenulates like Spirobrachia and 534 Lamelisabella there is a pair of giant axons extended from the giant unipolar perikarya located in the brain $[20,22]$. In small frenulates like Nereilinum there is only one giant axon, and it goes only along one side of the ventral ciliary field [22]. In frenulates the

537 giant axons extend only untill the girdle of hook-shaped chaetae located approximately 538 in the middle of the trunk, whereas in the vestimentiferans untill the end of the trunk.

539 Giant axons provide a rapid contraction of the longitudinal musculature, serving as so540 called "flight response" - in the frenulates and vestimentiferans it is the retraction of the 541 body deep into the tube at the moment of danger (i.e. claws of crabs Bythograea). 542 Frenulates anchored to the wall of the tube with means of girdle chaetae, and the 543 vestimentiferans - the chaetae of opisthosome. That is why the giant axons reach only 544 girdle in frenulates, and in the vestimentiferans - to the opistosome. There are no giant axons in Osedax and Sclerolinum.

546 Thus, the nerve cord in siboglinids is arranged in the similar way. In the anterior part of 547 the body the paired strands of the nerve cord associated with the ventral ciliary field. In 
548 all groups, the nerve cord lies entirely within the epidermis and contains giant axons.

549 The ventral nerve cord is not ganglionated for the most part of its length. The difference

550 in the nervous systems is that the frenulates have a ganglionization in the opistosome,

551 which probably indicates its greater mobility.

\section{Annelid ventral nerve cord in siboglinids}

554 Siboglinids have intraepidermal paired medullary ventral nerve cord containing the giant 555 axons (except Sclerolinum and Osedax) and associated with the ventral ciliary field.

556 What features siboglinids share with the possible sister group of annelids?

557 Intraepidermal nervous system is also known in species of Opheliidae, Spionidae, 558 Syllidae, Maldaniidae, Cossuridae, Polygordiidae, Protodrillidae etc as well as basal

559 radiation Chaetopteridae, Magelonidae and Oweniidae [47,60-62]. Also, meiobenthic

560 forms like Polygordiidae, Protodrilidae, Dinophiilidae have intraepidermal nervous

561 system. So far, it is hard to tell the functional advantages of the intraepidermal nervous system or evolutionary aspects of it. Perhaps it is simply common among the sessile or meiobenthic forms.

564 Paired nerves in most annelids are found at the larval stages of Errantia, Sedentaria and their sister clade [48,52,63-69], whereas in adult annelids the nerve cord is

566 organized in surprising range of levels: eighter single, paired, trineural, or pentaneural $567[47,60,70,71]$. Based on presence of the paired nerve cords in the hypothetical sister clades Cirratulida and Sabellida [39,72] and paired organization of the nerve cord in siboglinids, we can conclude that the paired nerve strands within the ventral nerve cord

570 might be ancestral feature for siboglinids (Fig 12).

571 Lack of ganglia in medullary nerve cord in long vestimentum/forepart and trunk 572 segments of vestimentiferans and frenulates, and their presence in each segment of mobile frenulate opisthosome is unusual for the most annelids exhibiting the uniform 
574 structure of the nerve cord along worm body as eighter medullar, or ganglionated one

$575[47,60,70,71]$. Non-uniform ventral nerve cord is known in oweniids: nerve cord 576 exchibits medullary state in elongated anterior segments and ganglionated-like state in 577 short posterior segments $[44,52,73]$. We assume in siboglinids medullary state of nerve 578 cords in elongated segments is due to regular innervation of the structures in the 579 segments which is convergent to the state of oweniid nerve cord.

580 The pattern of the segmental neurite bundles in vestimentiferans is similar to what we 581 know in oweniids [44,52,73]: numerous and anastomosing in long segments and condensed single bundle in short opisthosomal segments. This pattern could be a reflection of the elongation of the segments.

584 Giant axons and giant perikarya are common among annelids, mainly in large forms

$585[71,74]$. Common feature of most annelids to have multicellular or unicellular giant fibres extending from the giant somata usually lying in subesophageal ganglia and/ or other segmental ganglia. In vestimentiferans it is known a pair of giant perikarya, whereas in Riftia we detected at least four pairs of somata lying in the area of supraesophageal ganglion. Among annelids only in sabellids, like large Myxicola infundibulum and

590 Sabella pavonina, the giant perikarya lie in supraesophageal ganglion [74]. So, the 591 vestimentiferans share with sabellids the similar position of the giant perikarya in the supraesophageal ganglion.

Vestimentiferans together with the rest siboglinids have the ventral ciliary field bordered

594 by a pair of strands of the nerve cord. The ciliary field is not common among sexually 595 matured annelids. The structure is known in progenetic Dinophilus gyrociliatus $[75,76]$ and used for gliding. There is an observation that tiny frenulate Nereilinum murmanicum uses the ciliary field to glide vertically along its tube [23]. Other functions of the ventral ciliary fields in siboglinids remains theoretical [5]. Thus, it is the paired sturucture of the ventral nerve cord that siboglinids share with the possible annelid sister groups (Fig 12). 


\section{Brain ogranization in vestimentiferans}

602 The differences in brain structure of vestimentiferan species are mainly in the shape of

603 their brains and the presence/absence of cuticule structures $[6,7,10-12,15,54]$.

604 Riftia pachyptila's brain has heart-like shape at the transverse section with significatly

605 developed dorso-lateral lobes (Fig 5, 8A-D). Brain of Ridgeia piscesae has triangular

606 shape at transverse section with wide ventral side [10]. Brain of Lamellibrachia luymesi

607 has oval transverse shape [6]. These two latter vestimentiferan species have less

608 developed dorso-lateral lobes in comparison to Riftia (S5 Fig). Rifia is known to possess

609340 tentacles per lamellae and 335 lamellae on each side of the obturaculum whereas

61070 lamellae in Escarpia is the maximum lamellae number among the rest

611 vestimentiferans $[7,77,78]$. This could be the explanation of the presence of the

612 enlarged dorso-lateral lobes in Riftia's brain. Notably, inspite of the brain shape

613 differences, tentacle nerves originate from the same dorso-lateral areas of the brain

614 neuropile in Riftia and all other vestimentiferans.

615 Cuticle schield protects ventral side of the brain that has a direct contact with the tube or

616 ambient environment in all studied vestimentiferans as well as in Riftia (Fig 10G)

$617[6,10,11,15]$. The dorsal and frontal sides of the brain are covered by tentacles and

618 obturacules (Figs 4, 5). Additionaly, brain can be penetrated by cuticle shifts and plates

619 extending from the cuticle of tentacle lamellae, as in L. luymesi, R. piscesae, O. alvinae,

620 but not in Riftia $[6,11,15]$.

\section{Annelid brain in vestimentiferans}

623 The juvenile vestimentiferans preserve the gut rudiment what assist to make

624 homologization of the brain parts of the gutless siboglinids with the supra- and 625 subesophageal ganglia of typical annelids. 
626 The brain of the vestimentiferans lies completely in the epidermis at the anteriormost

627 part of the vestimentum. It is the large and dense mass of the neuropile which looks like 628 single entity, non-subdivided into the supraesophageal and subesophageal ganglia, as

629 in most annelids [60]. Following the idea suggested by Jones and Gardiner [8] we 630 assume that to the part of the brain of the vestimentiferans lying dorsally to the enteral 631 coelomic channel can be homologized with the supraesophageal ganglion (Figs 4, 8 A$632 \mathrm{D}, 11)$, whereas the part of the brain lying ventrally to the enteral coelomic channel with the subesophageal ganglion (Figs 4, $8 \mathrm{E}-\mathrm{H}, 11$ ).

Fig 11. Hypothetical vestimentiferan brain origin.

636 A - supra- and subesophageal ganglia in annelids (after [47]). B - hypothetical 637 transitional state. C - vestimentiferan brain. APN - neurite bundles of palps, $B$ - brain, $638 C$ - commissure of sbg, CC - circumesophageal connectives, $D C-$ dorsal commissure, $639 D R C C$ - dorsal (posterior) root of the CC, GC - enteral coelom, LNT - longitudinal 640 nerve tracts projecting from the ventral nerve cord into the brain, sbg - subesophageal 641 ganglion, SBC - subenteral commissure, spg - supraesophageal ganglion (which is 642 brain in annelids), SPC - supraenteral commissure, VRCC - ventral (anterior) root of 643 CC, TEN -neurite bundles of tentacles (palps).

645 Longitudinal nerve tracts $(L N T)$ lie ventrally in the posterior brain, while in the anterior 646 brain tracts run symmetrically right and left to the enteral coelomic channel and connect 647 each other by transverse commissures in the dorsal part of the anteriormost part of the 648 brain. Thus, LNT can be homologized with the circumesophageal connectives of annelids (Figs 9, 11). In annelids the circumesophageal connectives enter the brain and 650 bifurcate into ventral and dorsal roots [43,79-83]. Each root connects by a pair of dorsal and ventral commissures. Thus, in the annelid supraesophageal ganglion, there are two 
652 pairs of transverse commissures: a dorsal pair and ventral one $[43,47,81,83,84]$. In

653 vestimentiferans' dorsal brain part two transverse commissures can be distinguished:

654 the dorsal commissure consisting of couple of transverse bundles, and the supraenteral

655 commissure. Both commissures connect the nerve bundles of the longitudinal nerve

656 tracts. We suppose that the dorsal and supraenteral commissures of the brain of

657 vestimentiferans can be homologized with dorsal and ventral pairs of the commissures

658 of the supraesophageal ganglion of typical annelids (Fig 11).

659 Posteriorly, longitudinal nerve tracts pass through the ventral part of the brain and come

660 into the ventral nerve cord as the circumesophageal connectives in the annelid brain

661 and continue as longitudinal connectives of the ventral nerve cord [84].

662 The innervation of numerous tentacles of $R$. pachyptila occurs from the neuropile of the 663 lateral brain lobes (NE) containing radial tentacle neurite bundles (Figs 7, 8 A-D, 11C).

664 Neuropiles of the lateral lobes adjoin the longitudinal nerve tracts which are possible 665 homologues to the circumesophageal connectives (Fig 11). In annelids, the most part of 666 the peristomial palps are innervated from the circumesophageal connectives $[43,47]$.

667 Previously, tentacles of vestimentiferans were homologised with palps of polychates

668 [31], although based on differences in the external and internal structures (lack of 669 ciliated grooves, absence of longitudinal support rods and the presence of the afferent 670 and efferent blood vessels inside each tentacle) this homology was considered as 671 doubtful [58]. Our data on the innervation of the tentacles of Riftia proves the annelid 672 palps hypothesis of the vestimentiferan tentacles (Fig 11). But in the vestimentiferans 673 (especially Riftia) the parts of longitudinal nerve tracts and neuropile of the lateral brain 674 lobes are incomparably larger then corresponding neural structures in annelids, 675 because the tentacle apparatus of vestimentiferans is significantly developed. The 676 similar correlation between sizes of the tentacle crowns and brains are clearly seen in 677 oweniids and sabellids. The brain of oweniids with simple gill tentacles is just a 
678 transverse commissure passing in the epidermis dorsal to the digestive tract $[44,73]$,

679 whereas in sabellids with the large complecated tentacle crown serving for food 680 collection the brain consists of main four transverse commisures and many other 681 additional neural structures [43].

682 To summarize, the vestimentiferan brain shows similarity to the annelid brain 683 organization if we accept the idea of Jones and Gardiner [8] that the brain is a result of 684 the union of the supra- and subesophageal ganglia. In the dorsal part of the 685 vestimentiferan brain (=supraesophageal ganglion) we found homologues of the dorsal 686 and ventral pairs of the transverse commissures. The annelid brain shows remarkable 687 variety of the organization $[46,82,85,86]$. Our comparative anatomical approache shows 688 that the structure of the vestimentiferan brain and nervous system does not go beyond 689 this diversity of the brain and the nervous system of annelids.

690 Selivanova et al. [87] conducted a single immunoreactive study on brains of 691 vestimentiferan Ridgeia piscesae and identified 60 FMRFamide-immunoreactive 692 neurons in posterior brain and 24 neurons in ventral part of the brain and single FMRF693 amide IR-like processes in the medial zone of the brain neuropile. These specific 694 FMRFamide IR-like correspond to the following components of the brain of Riftia 695 pachyptila: posterior median perikarya aggregations ( $p m p$, Figs 7; 8E-H; S6F Fig), 696 ventrolateral lobe and posterior part of ventral lobe of tripartite ventral aggregation of 697 perikarya (Ivtp, vvtp, Figs 5; 6; 7; 8E-H; S6 A-D Figs) and vertical median bundles (VAN, 698 VPN, Figs 6; S10 Fig). The effect of FMRFamide mediator are shown to support the 699 heart pulsation, and tone of the esophagus and body walls in Nereis virens and 700 Sabellastarte magnifica $[88,89]$. In molluscs, FMRF-amide mediator is known to excite 701 and inhibit heartbeat [90], while in insects it controls heart function, somatic 702 musculature, crop and salivary glands [91]. Indeed, FMRFamide IR-elements in the 703 brain of Riftia are close to coelomic channels containing the rudimentary gut and 
704 obturacule blood vessels ( $m$ mp, VAN, VPN, Figs 6, 7) and to the ventral wall of the body

705 (Ivtp, vvtp, Figs 5; 6; 7). Perhaps the mentioned brain components of the 706 vestimentiferan brain are related to the functioning of the heart, gut and musculature of 707 the body wall.

\section{Evolutionary aspects of siboglinid brain}

710 Vestimentiferans of genera Riftia, Ridgeia, Oasisia, Lamellibrachia and Osedax are the 711 only siboglinids so far, whose brains were studied in detail $[5,9,11,12,15,26,27,87]$ and 712 present study]. Their brains compeletely lying in the ventral body epidermis and so far in spite of the fact that Osedax does not have gut rudiment as Riftia, it is still possible to

714 find similar structures helping us to homologize parts of brains among siboglinids.

715 First, homologization of dorsalmost commissures in brain of Riftia $(D C)$ and anterior 716 commissure in Osedax $(A C B R)$. They could be homologous to each other based on 717 anteriormost position in the brains in both siboglinids as well as based on neurites originating from them. Various vertical neurite bundles originating from these dorsalmost commissures in vestimentimentiferans and Osedax (DC in Riftia and ACBR in Osedax) and innervate anterior structures: 1) obturacule neurites in vestimentiferans ( $O B N$ in Riftia) and antero-dorsal nerves or anterior nerve net in Osedax ( $A D N$ and $A N N$, Fig 12; see Fig 2 in Worsaae et al., 2016), 2) palp neurites in Riftia (TEN) and Osedax (PN).

Second, homologization of palp neurites in Riftia (TEN) and Osedax (PN) based on the similar origin of lateral parts of the anterior most commissures in Riftia (DC) and Osedax $(A C B R$, Fig 12). 
729 Relation among the siboglinid groups from a combination of recent phylogenetic trees:

730 clade of frenulates resolved based on cladistic analysis [18], interrelationship of 731 siboglinid clades based on phylogenetic and phylogenomic data [17,92]; annelid 732 outgroups based on phylogenomic data [39]. Neural characters for homologization of 733 cerebral elements of siboglinids and annelid sister groups are listed (1-8). Neural 734 diagrams include sagittal views (upper row) and dorsal views (lower row) with 735 disposition of the cerebral elements in the anteriormost end of the worms. Perikarya shown in gray blue. Anterior ends at the top. Dashed lines show hypothesized brain boundary in the siboglinid ancestor. Cerebral elements drawn based on larvae of vestimentiferan Riftia pachyptila [14], adult of vestimentiferan Riftia pachyptila (this study); Osedax knutei (=O. "nudepalp E", [27,93]); frenulates Polybrachia annulata, and

740 Siboglinum caulleryi [19,20], Nereilinum murmanicum [23], cirratulid Cirratulus cf. cirratus [50], sabellid Euchone papillosa [43]. Sclerolinum's cerebral elements of the ventral brain are not shown. $\mathrm{H} 1$ is a combination of the hypothesized ancestral siboglinid states. ACBR - anterior commissure of the brain, $A D N$ - antero-dorsal nerve, aga - ganglion-like aggregation at base of TEC, $A N N$ - anterior nerve net, $B$ - brain, $C$ - commissure in sbg, CC - circumesophageal connectives, COM - commissure, $C O N-$ 746 connective, DC - dorsal commissure, DRCC - dorsal (posterior) root of the CC, GC enteral coelom, $L L N$ - lateral longitudinal neurite bundles in the brain, $L N T$ - longitudinal nerve tracts projecting from the VNC into the brain, $M C C$ - middle cross commissure, $N A$ - nerve ring (after [20]) or brain ring (after [23]), OBN - obturacular neurites, PCBR -

750 posterior commissure of the brain, $P N$ - palp nerve, TEC - tentacular commussure, 751 TEN - neurite bundles of tentacles (palps), SBC - subenteral commissure, sbg subesophageal ganglion, SPC - supraenteral commissure, spg - supraesophageal ganglion, VAN - anterior vertical median bundles, VNC - ventral nerve cord, VRCC -

754 ventral (anterior) root of CC. 
756 Third, homologization of the supraenteral commissure in Riftia (SPC) and the anterior part of posterior commissure in Osedax (PCBR, Fig 12). In the brain of Riftia (present study) and Osedax [27] there are crossing neurites: in the median areas of the brains in Riftia (VAN) and Osedax (MCC). Based on the presence and position of crossing neurites, we consider these commissures which are connected by crossing neurites homologous to each other. This means that the thick posterior commissure in Osedax $(P C B R)$ is homologous to the union of supra- and subenteral commissures in vestimentiferan brain (Fig 12). So, if in Osedax gut rudiment has been remained, it would pass throught the PCBR.

Forth, based on listed above homologozations we consider the longitudinal nerve tracks in Riftia (LNT) are possibly homologous to lateral longitudinal bundles in Oseadx (LLN), and both are homologous to the circumesophageal connectives in the brain of annelids (Fig 12).

769 Organization of the brain of frenulates, sister group to all other siboglinids [2,92] are 770 important for the analyisis of the ancestral state of the siboglinid brain. Although their 771 brains were studied in less details, but it is known in the dorsal epidermis in Polybrachia annulata, Siboglinum caulleryi there is a dorsal commissure $[19,20]$, and in Nereilinum murmanicum, S. modestum and S. subligatum there are two dorsal commissures [23].

774 These commissures in frenulates give rise the neurite bundles to anterior appendages. We consider that these dorsal commissures (NR, TEC) bearing anterior appendages' 776 nerves in frenulates (Fig 12) could be compared with the anterior commissures in 777 ventral brain of vestimentiferans and Osedax ( $D C$ and $A C B R$, respectively) bearing 778 nerves to palps. Moreover, we assume that according to innervation pattern, the anterior appendages in frenulates are also annelid palps. 
780 Brain of Sclerolinum is very simple structure lying completely on the ventral side and

781 having two layeres: apical perikarya and basal neuropile [28]. Due to the described 782 simpilicity of the brain structure we do not homologize it with other siboglinids and annelids.

784 Intriguing question is what the ancestral state of the brain of siboglinid was and how it was evolved? Besides the frenulates, vestimentiferan metatrochophores have the commissures and perikarya in the dorsal epidermis [14]. And sister clades to Siboglinidae, Cirratulidae and Sabellidae (according to [39]), have well developed supraesophageal brain on the dorsal side of the body $[43,50]$. It is reasonable to hypothesize that the presence of the commissure, lying dorsally to the gut and giving rise neurite bundles to palps might be the ancestral state of the siboglinid brain (Fig 12).

\section{Conclusions}

793 Our microscopical study and 3D reconstruction of the central nervous system of the

794 giant vestimentiferan tubeworm Riftia pachyptila allowed to reveal the structure of the

795 brain and ventral nerve cord.

796 Brain in adult vestimentiferans is a product of fusion of supraesophageal and

797 subesophageal ganglia. In the part homologized with the supraesophageal ganglion

798 there are two commissures: double dorsal commissure and single supraenteral

799 commissures. In the subesophageal part there is the subenteral commissure. Based on

800 the innervation of the anterior appendages from the longitudinal nerve tracts which are

801 homologous to the circumesophageal connectives, tentacles of vestimentiferans are 802 annelid palps. The innervation of the obturacles is different and will be discussed in the 803 following publication. The ventral nerve cord of vestimentiferans is intraepidermal, 804 paired, associated with the ciliary field, not ganglionated for the most part of its length. 805 The latter is the feature of the elongation of the segments. In Riftia there is one giant 
806 axon in the ventral nerve cord in trunk which is the product of fusion of several axons.

807 The giant axon extends from at least four giant perikarya in Riftia. Suprisingly, the giant

808 perikarya lie in the supraesophageal brain part of Riftia, like in sabellid annelids.

809 The central nervous system of vestimentiferans and other siboglinids are arranged in

810 the same way: anterior ventral brain and paired ventral nerve cord. All siboglinids share

811 the same features of the ventral nerve cord: intraepidermal paired nerve cord 812 associated with the ventral ciliary field (Fig 12). The comparative analysis of brain

813 structures of the siboglinids suggests that the dorsal commissure bearing palp nerves is

814 common for all siboglinids: it can be found in dorsal epidermis of frenulates and

815 vestimentiferan larvae, in supraesophegeal part of vestimentiferan brains and possibly it

816 is anterior commissure found in Osedax (Fig 12). The difference in the nervous systems

817 is that the vestimentiferans have a large and significatly differentiated brain which is

818 reflection of the high development of the palp apparatus. Osedax, frenulates and

819 Sclerolinum have less developed brain. Frenulates and Sclerolinum have good

820 ganglionization in the opisthosome, which probably indicates its high mobility.

821 The comparative anatomical analysis of the neural structures of the siboglinids and

822 sister annelid clades lead us to hypothesize that the presence of the commissure, lying

823 dorsally to the gut and giving rise neurite bundles to palps might be the ancestral state

824 of the siboglinid brain.

\section{Acknowledgments}

826 We thank the chief scientists of Laboratory of Ocean Benthic Fauna and crews of RVs

827 and ROVs of Shirshov Institute of Oceanology of the Russian Academy of Science for

828 assistance and their continuous help in collecting the material. 
831 1. Schulze A, Halanych KM. Siboglinid evolution shaped by habitat preference and

832 sulfide tolerance. Hydrobiologia. 2003;496: 199-205.

833 doi:10.1023/A:1026192715095

2. Halanych KM. Molecular phylogeny of siboglinid annelids (a.k.a. pogonophorans): a review. Hydrobiologia. 2005;535-536: 297-307. doi:10.1007/s10750-004-1437-

3. Karaseva NP, Rimskaya-Korsakova NN, Galkin SV, Malakhov VV. Taxonomy, geographical and bathymetric distribution of vestimentiferan tubeworms (Annelida, Siboglinidae). Biol Bull. 2016;43. doi:10.1134/S1062359016090132

4. Webb M. Lamellibrachia barhami, Gen. Nov., Sp. Nov., (Pogonophora), from the Northeast Pacific. Bull Mar Sci. 1969;19: 18-47.

5. van der Land J, Nørrevang A. The systematic position of Lamellibrachia (Annelida, Vestimentifera). Zeitschrift für Zool Syst und Evol. 1975;1: 86-101.

6. van der Land J, Nørrevang A. Structure and Relationships of Lamellibrachia (Annelida, Vestimentifera). Det K Danske Vidensk Selsk Biol Skr. 1977;21: 1-102.

846 7. Jones ML. Riftia pachyptila Jones: Observations on the Vestimentiferan Worm from the Galapagos Rift. Science. 1981;213: 333-336. doi:10.1126/science.213.4505.333

8. Jones M, Gardiner S. Evidence for a transient digestive tract in Vestimentifera. Proc Biol Soc Wash. 1988;101: 423-433.

9. Gardiner S, Jones M. Vestimentifera. In: Harrison F, Rice M, editors. Microscopic Anatomy of Invertebrates, Volume 12: Onychophora, Chilopoda, and Lesser Protostomata. 1993. pp. 371-460.

10. Malakhov V, Popelyaev I, Galkin S. Microscopic anatomy of Ridgeia phaeophiale Jones, 1985 (Pogonophora, Vestimentifera) and the problem of the position of Vestimentifera in the system of animal kingdom. 2. Integument, nerve system, 
connective tissue, musculature. Biol Morya. 1996;22: 139-147.

858 11. Karaseva NP, Malakhov V V., Galkin S V. The morphology and anatomy of the vestimentiferan worm Oasisia alvinae Jones, 1985 (Annelida: Siboglinidae). II. Integument, nervous system and musculature. Russ J Mar Biol. 2012;38: 10-21. doi:10.1134/S1063074012010075

12. Miyamoto N, Shinozaki A, Fujiwara Y. Neuroanatomy of the vestimentiferan tubeworm Lamellibrachia satsuma provides insights into the evolution of the polychaete nervous system. PLoS One. 2013;8: e55151. doi:10.1371/journal.pone.0055151

13. Jones ML, Gardiner SL. On the Early Development of the Vestimentiferan Tube Worm Ridgeia sp. and Observations on the Nervous System and Trophosome of Ridgeia sp. and Riftia pachyptila. Biol Bull. 1989;177: 254-276. doi:10.2307/1541941

14. Bright M, Eichinger I, von Salvini-Plawen L. The metatrochophore of a deep-sea hydrothermal vent vestimentiferan (Polychaeta: Siboglinidae). Org Divers Evol. 2012;13: 163-188. doi:10.1007/s13127-012-0117-z

15. Mamkaev Y V., Selivanova R V., Punin MY. Comparative anatomical investigation of the nervous system of Vestimentifera (Pogonophora). Biol Morya. 1999;25:

16. Southward EC. Siboga-Expeditie Pogonophora. Siboga-Expeditie Uitkomsten op Zool Bonatisch, Oceanogr en Geol Geb verzameld Ned Oost-Indië 1899-1900. 1961;25: 1-22.

879 17. Rouse GW, Goffredi SK, Vrijenhoek RC. Osedax: bone-eating marine worms with dwarf males. Science. 2004;305: 668-71. doi:10.1126/science.1098650

18. Rouse GW. A cladistic analysis of Siboglinidae Caullery , 1914 ( Polychaeta , 
19. Ivanov AV. The nervous system of Pogonophora. Zool zhurnal. 1958;37: 16821693.

20. Ivanov AV. Pogonophora. London: Academic Press; 1963.

21. Southward EC. A study of the structure of the opisthosoma of Siboglinum fiordicum. Zeitschrift fur Zool Syst und Evol Sonderh. 1975; 64-76.

22. Southward EC. Pogonophora. In: Harrison F, Westfall J, editors. Microscopic

23. Bubko O, Minichev Y. Nervous system of Nereilinum murmanicum Ivanov and Taxonomic Status of Pogonophora. Zool zhurnal. 1977;56: 1277-1287.

24. Halanych KM, Lutz RA, Vrijenhoek RC. Evolutionary origins and age of vestimentiferan tube-worms. Cah Biol Mar. 1998;39: 355-358.

25. Gupta BL, Little C. Studies on Pogonophora. 4. Fine structure of the cuticle and epidermis. Tissue Cell 2. 1970; 637-696.

26. Worsaae K, Rouse GW. The simplicity of males: dwarf males of four species of Osedax (Siboglinidae; Annelida) investigated by confocal laser scanning microscopy. J Morphol. 2010;271: 127-42. doi:10.1002/jmor.10786

27. Worsaae K, Rimskaya-Korsakova NN, Rouse GW. Neural reconstruction of boneeating Osedax spp. (Annelida) and evolution of the siboglinid nervous system. BMC Evol Biol. 2016;16: 83. doi:10.1186/s12862-016-0639-7

28. Eichinger I, Hourdez S, Bright M. Morphology, microanatomy and sequence data of Sclerolinum contortum (Siboglindae, Annelida) of the Gulf of Mexico. Org Divers Evol. 2013;13: 311-329. doi:10.1007/s13127-012-0121-3 
vents and cold-water seeps. Mar Biol. 1997;130: 141-149.

910

doi:10.1007/s002270050233

911

30. McHugh D. Molecular evidence that echiurans and pogonophorans are derived annelids. Proc Natl Acad Sci. 1997;94: 8006-8009. doi:10.1073/pnas.94.15.8006

31. Rouse GW, Fauchald K. Cladistics and polychaetes. Zool Scr. 1997;26: 139-204. doi:10.1111/j.1463-6409.1997.tb00412.x

32. Halanych KM. Unsegmented Annelids? Possible Origins of Four Lophotrochozoan Worm Taxa. Integr Comp Biol. 2002;42: 678-684. doi:10.1093/icb/42.3.678

33. Bleidorn C, Vogt L, Bartolomaeus T. A contribution to sedentary polychaete phylogeny using 18S rRNA sequence data. J Zool Syst Evol Res. 2003;41: 186195. doi:10.1046/j.1439-0469.2003.00212.x

34. Schulze A. Phylogeny of Vestimentifera (Siboglinidae, Annelida) inferred from morphology. Zool Scr. 2003;32: 321-342. doi:10.1046/j.1463-6409.2003.00119.x

35. Liwanow N, Porfirjewa N. Die Organisation der Pogonophoren und deren

36. Rousset V, Rouse GW, Siddall ME, Tillier A, Pleijel F. Cladistics 18S rRNA, $28 \mathrm{~S}$ rRNA and morphological data. Cladistics. 2004;20: 518-533.

37. Uschakov P V. Eine neue form aus der Familie Sabellidae (Polychaeta). Zool Anz. 1933;104: 205-208.

38. Weigert A, Helm C, Meyer M, Nickel B, Arendt D, Hausdorf B, et al. Illuminating the base of the annelid tree using transcriptomics. Mol Biol Evol. 2014;31: 1391401. doi:10.1093/molbev/msu080

39. Struck TH, Golombek A, Weigert A, Franke FA, Westheide W, Purschke G, et al. 
935

936

937

938

939

940

941

942

943

944

945

946

947

948

949

950

951

952

953

954

955

956

957

958

959

960

40. Zrzavý J, Ríha P, Piálek L, Janouskovec J. Phylogeny of Annelida

(Lophotrochozoa): total-evidence analysis of morphology and six genes. BMC

Evol Biol. 2009;9: 189. doi:10.1186/1471-2148-9-189

41. Andrade SCS, Novo M, Kawauchi GY, Worsaae K, Pleijel F, Giribet G, et al. Articulating “ archiannelids ": Phylogenomics and annelid relationships, with emphasis on meiofaunal taxa. Mol Biol Evol. 2015; doi:10.1093/molbev/msv157

42. Hess WN. Nervous system of the earthworm, Lumbricus terrestris L. J Morphol. 1925;40: 235-259.

43. Orrhage L. On the structure and homologues of the anterior end of the polychaete families sabellidae and serpulidae. Zoomorphology. 1980;96: 113-167. doi:10.1007/BF00310081

44. Rimskaya-Korsakova NN, Kristof A, Malakhov V V, Wanninger A. Neural architecture of Galathowenia oculata Zach, 1923 (Oweniidae, Annelida). Front Zool. 2016;13: 1-19. doi:10.1186/s12983-016-0136-2

45. Hessling R, Westheide W. CLSM analysis of development and structure of the central nervous system of Enchytraeus crypticus ("Oligochaeta", Enchytraeidae). Zoomorphology. 1999;119: 37-47. doi:10.1007/s004350050079

46. Müller MCM. Nerve development, growth and differentiation during regeneration in Enchytraeus fragmentosus and Stylaria lacustris (Oligochaeta). Dev Growth Differ. 2004;46: 471-478. doi:10.1111/j.1440-169x.2004.00763.x

47. Orrhage L, Müller MCM. Morphology of the nervous system of Polychaeta (Annelida). Hydrobiologia. 2005;535-536: 79-111.

48. Koza A, Wilhelm M, Hiripi L, Elekes K, Csoknya M. Embryogenesis of the serotonergic system in the earthworm Eisenia fetida (Annelida, Oligochaeta): Immunohistochemical and biochemical studies. J Comp Neurol. Wiley Online Library; 2006;497: 451-467. doi:10.1002/cne 
961 49. Weidhase M, Bleidorn C, Helm C. Structure and anterior regeneration of musculature and nervous system in Cirratulus cf. cirratus (Cirratulidae, Annelida). J Morphol. 2014;275: 1-13. doi:10.1002/jmor.20316

50. Weidhase M, Helm C, Bleidorn C. Morphological investigations of posttraumatic regeneration in Timarete cf. punctata (Annelida: Cirratulidae). Zool Lett. BioMed Central; 2015;1: 1-16.

51. Zattara EE, Bely AE. Fine taxonomic sampling of nervous systems within Naididae (Annelida: Clitellata) reveals evolutionary lability and revised homologies of annelid neural components. Front Zool. 2015;12. doi:10.1186/s12983-0150100-6

52. Helm C, Vöcking O, Kourtesis I, Hausen H. Owenia fusiformis--a basally branching annelid suitable for studying ancestral features of annelid neural development. BMC Evol Biol. BioMed Central; 2016;16: 129.

53. Land J, Norrevang A. Structure and relationships of Lamellibrachia (Annelida, Vestimentifera). Det K Danske Vidensk Selsk Biol Skr. 1977;21: 1-102.

54. Andersen AC, Hourdez S, Marie B, Jollivet D, Lallier FH, Sibuet M. Escarpia southwardae sp . nov ., a new species of vestimentiferan tubeworm ( Annelida , Siboglinidae ) from West African cold seeps. 2004;999: 980-999. doi:10.1139/Z04-049

55. Webb M. Studies on Lamellibrachia barhami (Pogonophora) II. The reproductive organs. Zool Jb Anat. 1977;97: 455-481.

56. Bakke T. Settling of the larvae of Siboglinum fiordicum Webb (Pogonophora) in the laboratory. Sarsia. Taylor \& Francis; 1974;56: 57-70.

57. Bakke T. Development of Siboglinum fiordicum Webb (Pogonophora) after metamorphosis. Sarsia. Taylor \& Francis; 1977;63: 65-73. 
59. Webb M. The posterior extremity of Siboglinum fiordicum (Pogonophora). Sarsia. Taylor \& Francis; 1964;15: 33-36.

60. Bullock T. Annelida, vol 1. In: Bullock T, Horridge G, editors. c. W. H. Free. San Francisco; 1965. pp. 661-789.

61. Jones ML. On the morphology, feeding, and behavior of Magelona sp. Biol Bull. 1968;134: 272-297.

62. Zhadan A, Vortsepneva E, Tzetlin A. Ontogenetic development and functioning of the anterior end of Cossura pygodactylata Jones, 1956 (Annelida: Cossuridae). Zoomorphology. 2015;134: 509-521. doi:10.1007/s00435-015-0282-7 Bonellia viridis. J Morphol. 2002;252: 100-13. doi:10.1002/jmor.1093

64. Hessling R. Metameric organisation of the nervous system in developmental stages of Urechis caupo (Echiura) and its phylogenetic implications. Zoomorphology. 2002;121. doi:10.1007/s00435-002-0059-7

65. Voronezhskaya EE, Tsitrin EB, Nezlin LP. Neuronal development in larval polychaete Phyllodoce maculata (Phyllodocidae). J Comp Neurol. 2003;455: 299_ 309. doi:10.1002/cne. 10488

66. Brinkmann N, Wanninger A. Larval neurogenesis in Sabellaria alveolata reveals plasticity in polychaete neural patterning. Evol Dev. 2008;10: 606-618. doi:10.1111/j.1525-142X.2008.00275.x 
1013 68. Meyer NP, Carrillo-Baltodano A, Moore RE, Seaver EC. Nervous system development in lecithotrophic larval and juvenile stages of the annelid Capitella teleta. Front Zool. BioMed Central; 2015;12: 15.

69. Starunov V V, Voronezhskaya EE, Nezlin LP. Development of the nervous system in Platynereis dumerilii (Nereididae, Annelida). Front Zool. 2017;14: 27. doi:10.1186/s12983-017-0211-3

70. Golding D. Polychaeta. In: Harrison F, Gardiner S, editors. Microscopic Anatomy of Invertebrates, , Volume 7: Annelida. Harrison,. New York: Wiley-Liss, Inc.; 1992. pp. 1-418.

71. Purschke G. Annelida: Basal groups and Pleistoannelida. In: Schmidt-Rhaesa A, Harzsch S, Purschke G, editors. Structure and evolution of invertebrate nervous systems. Oxford Uni. Oxford University Press; 2015. pp. 254-312.

72. Struck TH, Paul C, Hill N, Hartmann S, Hosel C, Kube M, et al. Phylogenomic analyses unravel annelid evolution. Nature. 2011;471: 95-98.

73. Bubko O, Minichev Y. Nervous system of Oweniidae (Polychaeta). Zool zhurnal.

74. Nicol JAC. The giant axons of annelids. Q Rev Biol. 1948;23: 291-323. doi:10.1086/396594

75. Fofanova EG, Nezlin LP, Voronezhskaya EE. Ciliary and nervous structures in juvenile females of the annelid Dinophilus gyrociliatus (O. Schmidt, 1848) (Annelida: Polychaeta). Russ J Mar Biol. 2014;40: 43-52. doi:10.1134/S1063074014010040

76. Kerbl A, Fofanova EG, Mayorova TD, Voronezhskaya EE, Worsaae K. 
1039 77. Jones ML. On the Vestimentifera, new phylum: six new species, and other taxa, from hydrothermal vents and elsewhere. Bull Biol Soc Washingt. National Museum of Natural History, Biological Society of Washington; 1985;6: 117-158.

78. Rimskaya-Korsakova NN, Malakhov VV. Organization of the tentacular apparatus of the vestimentiferan tubeworm Riftia pachyptila, Jones 1981 (Annelida, Vestimentifera). Dokl Biol Sci. 2010;433. doi:10.1134/S001249661004006X

79. Rhode E. Histologische Untersuchungen über das Nervensystem der Chaetopoden. Zool Beitr. 1887;2: 1-81.

80. Gustafson G. Anatomische Studien über die Polychaeten Familien Amphinomidae und Euphrosynidae. Zool Bidr Upps. 1930; 305-471.

81. Orrhage L. Uber die Anatomie des zentralen Nervensystemes der sedentaren

82. Müller MCM, Berenzen A, Westheide W. Experiments on anterior regeneration in Polychaeten. Ein Beitrag zur Diskussion uber die Architektur des PolychaetenGehirns und uber den Begriff Palpen bei den Borstenwurmern. Ark fur Zool. 1967;19: 99-133.

83. Müller MCM, Henning L. Neurogenesis during regeneration in Dorvillea bermudensis (Dorvilleidae)--formation of the polychaete cephalic ground pattern. J Comp Neurol. 2004;471: 49-58.

84. Müller MCM. Polychaete nervous systems: Ground pattern and variations--cLS microscopy and the importance of novel characteristics in phylogenetic analysis. Integr Comp Biol. 2006;46: 125-33. doi:10.1093/icb/icj017 
(Annelida, Aeolosomatidae). Zoomorphology. 2000;120: 65-78.

1066 doi:10.1007/s004350000022

86. Müller MCM, Henning L. Ground plan of the polychaete brain--I. Patterns of nerve development during regeneration in Dorvillea bermudensis (Dorvilleidae). J Comp Neurol. 2004;471: 49-58. doi:10.1002/cne.20022

87. Selivanova R V, Punin MY, Mamkaev Y V. FMRFamide Immunoreactive Structures in the Nervous System of Vestimentiferan Species Ridgeia piscesae. Dokl Biol Sci. 1997;354: 257-259.

88. Diaz-Miranda L, de Motta GE, Garcia-Arrarás JE. Monoamines and neuropeptides as transmitters in the sedentary polychaete Sabellastarte magnifica: actions on the longitudinal muscle of the body wall. J Exp Zool Part A Ecol Genet Physiol. Wiley Online Library; 1992;263: 54-67.

89. Krajniak KG, Greenberg MJ. The localization of FMRFamide in the nervous and somatic tissues of Nereis virens and its effects upon the isolated esophagus. doi:https://doi.org/10.1016/0742-8413(92)90205-L

90. Painter G. A Survey of the Responses of Bivalve Hearts to the Molluscan Neuropeptide FMRFamide and to 5-Hydroxytryptamine. Biol Bull. 1982;162: 311. doi:10.2307/1540986

91. Krajniak KG. Annelid Endocrine Disruptors and a Survey of Invertebrate FMRFamide-Related Peptides. Integr Comp Biol. 2005;45: 88-96. doi:10.1093/icb/45.1.88 Phylogenomics of tubeworms (Siboglinidae, Annelida) and comparative performance of different reconstruction methods. Zool Scr. Wiley Online Library; 2017;46: 200-213. 
1091 93. Rouse GW, Goffredi SK, Johnson SB, Vrijenhoek RC. An inordinate fondness for

\section{Supporting Information}

\section{S1 Figure. Anteriormost brain of Riftia.}

1098 Histological cross section of the $79 \mathrm{~mm}$ long male. Level of the section shown at the 1099 diagram, right lower coner. amp - anterior median aggregation of perikarya, CU 1100 cuticle, CUP - cuticle schild, DC - dorsal commissure, DLN - dorsal area of the

1101 longitudinal bundles, dop - dorsal aggregation of perikarya, EP - epidermis, GC 1102 enteral coelom, $L N T$ - longitudinal nerve tracts projecting from the ventral nerve cord 1103 into the brain, $L R$ - undifferential tentacle lamellae, $N E$ - neuropile of the lateral brain 1104 lobes, nep - peripheral perikarya of the lateral brain lobes, $O B C$ - obturacular coelom, $1105 O B L$ - obturacular lobes, OBN - obturacular neurite bundles, OBV - obturacular blood 1106 vessels, SLN - supraenteral longitudinal neurite bundles, TE - free tentacles, TEN 1107 neurite bundles of tentacles (palps), vtp - tripartite ventral aggregation of perikarya.

\section{S2 Figure. Anterior and middle brain organization of Riftia.}

1110 A-B - histological cross sections of the $79 \mathrm{~mm}$ long male. Level of each section shown

1111 at the diagram, right lower coner. amp - anterior median aggregation of perikarya, CUP

1112 - cuticle schild, $D C$ - dorsal commissure, DLN - dorsal area of the longitudinal neurite

1113 bundles, dop - dorsal aggregation of perikarya, EP - epidermis, GC - enteral coelom,

$1114 L N T$ - longitudinal nerve tracts projecting from the ventral nerve cord into the brain, $L R$ 1115 - undifferential tentacle lamellae, Ivtp - ventrolateral perikarya of the vtp, NE 1116 neuropile of the lateral brain lobes, nep - peripheral perikarya of the lateral brain lobes, 
$1117 \mathrm{OBL}$ - obturacular lobes, $O B C$ - obturacular coelom, $O B N$ - obturacular neurite

1118 bundles, OBV - obturacular blood vessels, $p /$ - large perikarya, $p s$ - small perikarya,

1119 SLN - supraenteral longitudinal neurite bundles, TE - free tentacles, TEN -neurite

1120 bundles of tentacles (palps), VSN - vertical supraenteral neurite bundles, vtp - tripartite

1121 ventral aggregation of perikarya, vvtp - ventral perikarya of the vtp, $X X L$ - pair of

1122 prominent bundles of large longitudinal neurites (part of $L N T$ ).

1123

1124 S3 Figure. Posteriormost brain organization of Riftia.

1125 A-B - histological cross sections of the $79 \mathrm{~mm}$ long male. Level of the section shown at

1126 the diagram, right lower coner. CUP - cuticle schild, DC - dorsal commissure, DLN -

1127 dorsal area of the longitudinal neurite bundles, dop - dorsal aggregation of perikarya,

$1128 E P$ - epidermis, GA - giant axons, GC - enteral coelom, $L N C$ - lateral connectives,

$1129 L N T$ - longitudinal nerve tracts projecting from the ventral nerve cord into the brain, $L R$

1130 - undifferential tentacle lamellae, Ivtp - ventrolateral perikarya of the vtp, NE -

1131 neuropile of the lateral brain lobes, nep - peripheral perikarya of the lateral brain lobes,

$1132 O B C$ - obturacular coelom, $O B L$ - obturacular lobes, $O B N$ - obturacular neurites, $O B V$

1133 - obturacular blood vessels, $p /$ - large perikarya, $p m p$ - posterior median perikarya

1134 aggregation, $p s$ - small perikarya, SBC - subenteral commissure, SPC - supraenteral

1135 commissure, SLN - supraenteral longitudinal neurite bundles, TEN -neurite bundles of

1136 tentacles (palps), VPN- posterior vertical median bundles, vvtp - ventral perikarya of the

$1137 v t p$, VSN - vertical supraenteral neurite bundles.

1138

1139 S4 Figure. Intraepidermal position of the brain.

1140 A, B - schemes of sagittal and cross sections at levels (1-3) shown in (A). B - brain, CU

1141 - cuticle, CUP - cuticle schild, ECM - extracellular matrix, EP - epidermis, OBL -

1142 obturacular lobes, VE - vestimental process, VNC - ventral nerve cord. 
1144 S5 Figure. Neural elements in the bases of the undifferential tentacle lamellae.

1145 A - scheme of neural elements of the undifferential tentacle lamellae: perikarya and

1146 neurite bundles. B-D - tentacle lamellae bases on the dorsal, lateral and ventrolateral

1147 sides of the brain surface, respectively. ECM - extracellular matrix, EP - epidermis, IEP

1148 - epidermis of the internal lamellae wall, OEP - epidermis of the external lamellae wall,

$1149 L R$ - undifferential tentacle lamellae, NE - neuropile of the lateral brain lobes, nep -

1150 peripheral perikarya of the lateral brain lobes, $N B$ - neurite bunldes, $O B$ - obturaculum,

1151 pl-large perikarya, ps - small perikarya, TEN - neurite bundles of tentacles (palps).

\section{S6 Figure. Coelomic channels running through the brain.}

1154 3D models of Riftia brain. A, C, E - peripheric perikarya of the lateral brain lobes (nep) 1155 are on the dorsal side of the brain (purple). B, D, F - tripartite aggregation of perikarya $1156(v t p)$ is on the ventral side and under the obturacular and enteral coeloms (blue). View

1157 sides shown at the right lower corners of each images. Cube side is $255 \mu \mathrm{m}$. Dashed 1158 lines point neural elements under transparent structures. GC - enteral coelom, Ivtp 1159 ventrolateral perikarya of the vtp, nep - peripheral perikarya of the lateral brain lobes, 1160 OBC - obturacular coelom, pmp - posterior median perikarya aggregation, vtp 1161 tripartite ventral aggregation of perikarya, vvtp - ventral perikarya of the vtp.

\section{S7 Figure. Innervation of neuropile of the lateral brain lobes.}

1164 3D models of Riftia brain. A-C, $A^{\prime}-C^{\prime}$ - neuropile of the lateral brain lobes $(N E)$ 1165 associated with the longitudinal nerve tracts $(L N T)$. D-H - longitudinal nerve tracts 1166 projecting from the ventral nerve cord into the brain (LNT) and giving rise the prominent 1167 bundles of large longitudinal neurites $(X X L)$. I-J - peripheric perikarya (nep) and 1168 neuropile of the lateral brain lobes (NE). View sides shown at the right lower corners of 
1169 each images. Cube side is $255 \mu \mathrm{m}$. Dashed lines point neural elements under

1170 transparent structures. $D C$ - dorsal commissure, $D L N-$ dorsal area of the longitudinal

1171 bundles, GA - giant axons, GC - enteral coelom, LNC - lateral connectives, LNT -

1172 longitudinal nerve tracts projecting from the ventral nerve cord into the brain, NE -

1173 neuropile of the lateral brain lobes, nep - peripheral perikarya of the lateral brain lobes,

$1174 S B C$ - subenteral commissure, SPC - supraenteral commissure, vtp - tripartite ventral

1175 aggregation of perikarya, $X X L$ - pair of prominent bundles of large longitudinal nerve 1176 tracts (part of $L N T$ ).

1178 S8 Figure. 3D-models of anterior neural elements of Riftia brain.

1179 3D models of Riftia brain. A-C - overviews of supraenteral longitudinal neurite bundles

$1180(S L N)$ extending from the anterior median perikarya aggregation (amp); D-E - anterior 1181 median perikarya aggregation in association with the main cerebral elements: ventral 1182 tripartite aggragation (vtp), dorsal commissure $(D C)$ and supraenteral commissure 1183 (SPC); F-G - anterior median perikarya aggregation (amp) and dorsal commissure (DC) 1184 in association with the obturacular channels $(O B C)$. View sides shown at the right lower 1185 corners of each images. Cube side is $255 \mu \mathrm{m}$. Dashed lines point neural elements 1186 under transparent structures. amp - anterior median aggregation of perikarya, $D C$ 1187 dorsal commissure, GA - giant axons, GC - enteral coelom, $L N C$ - lateral connectives, 1188 OBC - obturacular coelom, SBC - subenteral commissure, SPC - supraenteral 1189 commissure, SLN - supraenteral longitudinal neurite bundles, VSN - vertical 1190 supraenteral neurite bundles, vtp - tripartite ventral aggregation of perikarya.

1192 S9 Figure. Obturacular innervation and giant neurons in Riftia brain.

1193 3D models of Riftia brain. A-C - disposition of obturacular neurite bundles (OBN) and 1194 dorsal longitudinal bundles $(D L N)$, D-F - origin of obturacular neurite bundles $(O B N)$ 
1195 from dorsal commissure, and neuropile of the lateral brain lobes (NE) from longitudinal

1196 nerve tracts (LNT). G-J - giant axons (GA) and position of giant perikarya (gap); K-L -

1197 position of giant neurons between the coelomic channels (OBC, GC). View sides shown

1198 at the right lower corners of each images. Cube side is $255 \mu \mathrm{m}$. Dashed lines point

1199 neural elements under transparent structures. $D C$ - dorsal commissure, $D L N-$ dorsal

1200 area of the longitudinal bundles, GA - giant axons, GC - enteral coelom, gap - giant

1201 perikarya, $L N T$ - longitudinal nerve tracts projecting from the VNC into the brain, NE -

1202 neuropile of the lateral brain lobes, nep - peripheral perikarya of the lateral brain lobes,

1203 OBC - obturacular coelom, OBN - obturacular neurites, SPC - supraenteral

1204 commissure, $X X L$ - pair of prominent bundles of large longitudinal nerve tracts (part of 1205 LNT).

1206

1207 S10 Figure. Vertical midbrain neurite bundles.

1208 3D models of Riftia brain. A-D - anterior (VAN) and posterior (VPN) vertical median

1209 bundles in between other midbrain structures, E-G - giant axons (GA) running inside the 1210 crossing anterior median bundles (VAN). View sides shown at the right lower corners of 1211 each images. Cube side is $255 \mu \mathrm{m}$. Dashed lines point neural elements under

1212 transparent structures. DC - dorsal commissure, GA - giant axons, GC - enteral 1213 coelom, gap - giant perikarya, LNC - lateral connectives, OBC - obturacular coelom, 1214 SBC - subenteral commissure, SLN - supraenteral longitudinal neurite bundles, SPC 1215 supraenteral commissure, VAN - anterior vertical median bundles, VPN - posterior 1216 vertical median bundles. 
A

B

C GC Ivtp

(1)

Nisto

Nots

1)

visures

ing

bistis

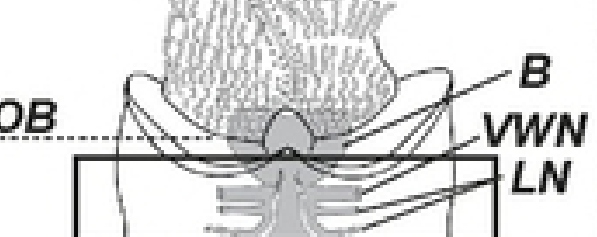

$N E$

nep:

nepti

NE

CNC

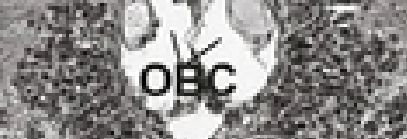

VNC

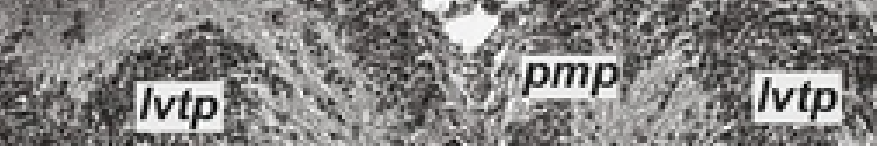

4.

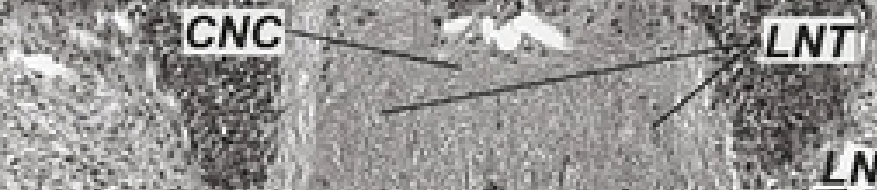

$\frac{3}{4}$

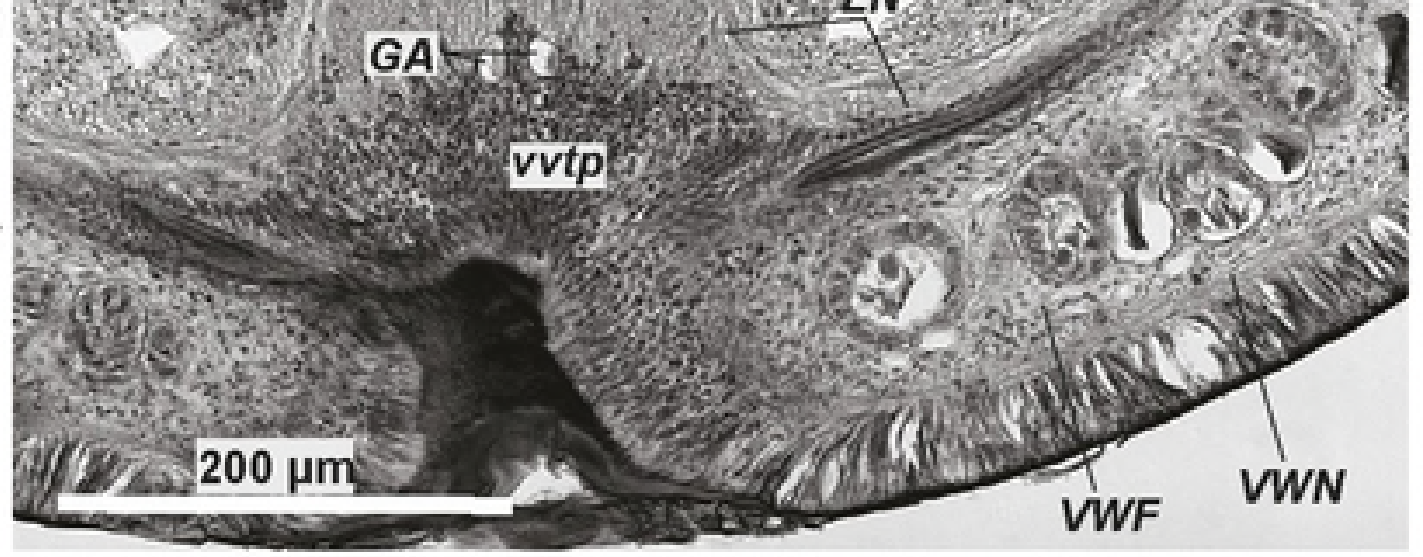

VT
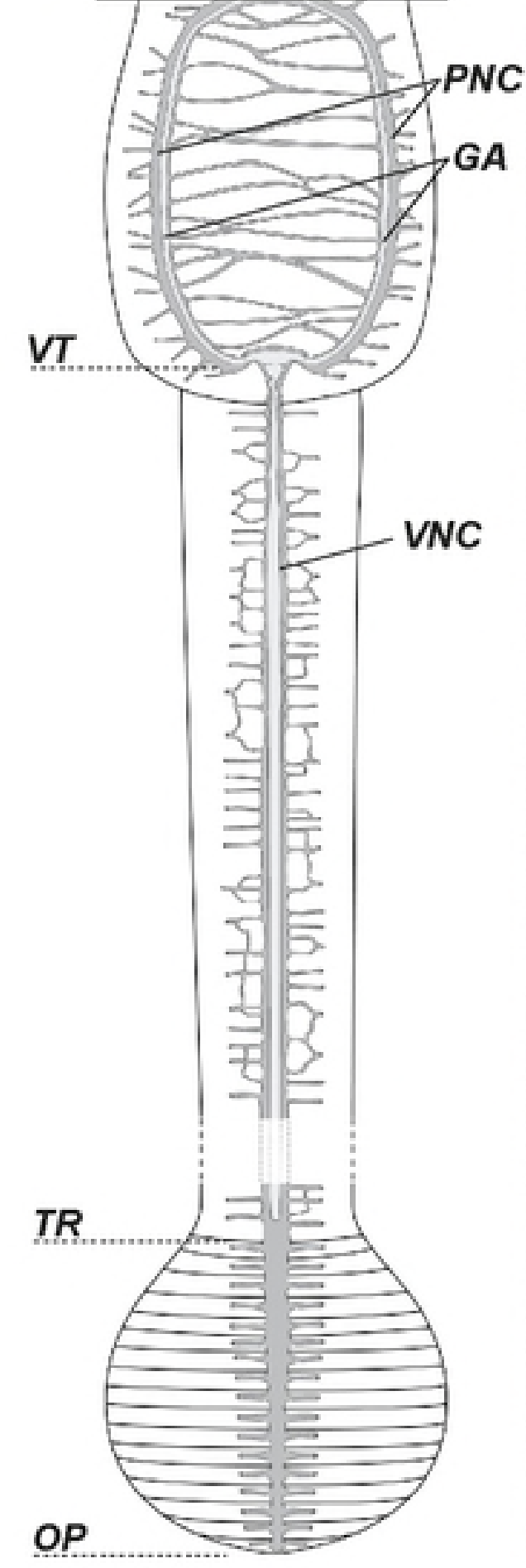

- $\mathrm{D}$.

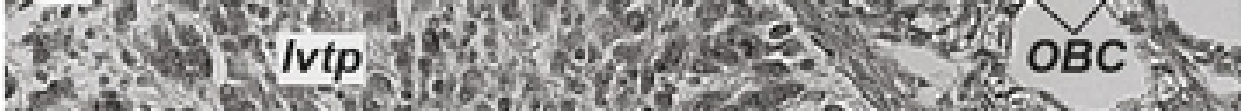

12 tench

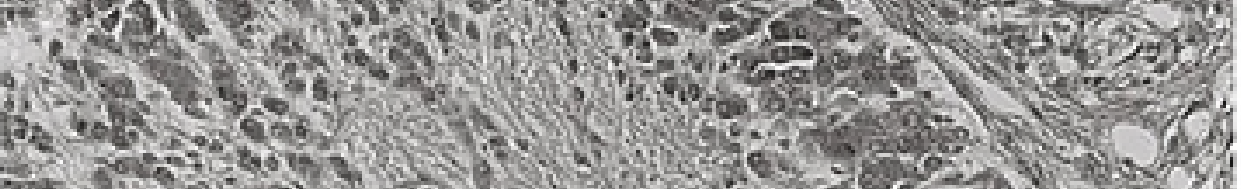

a
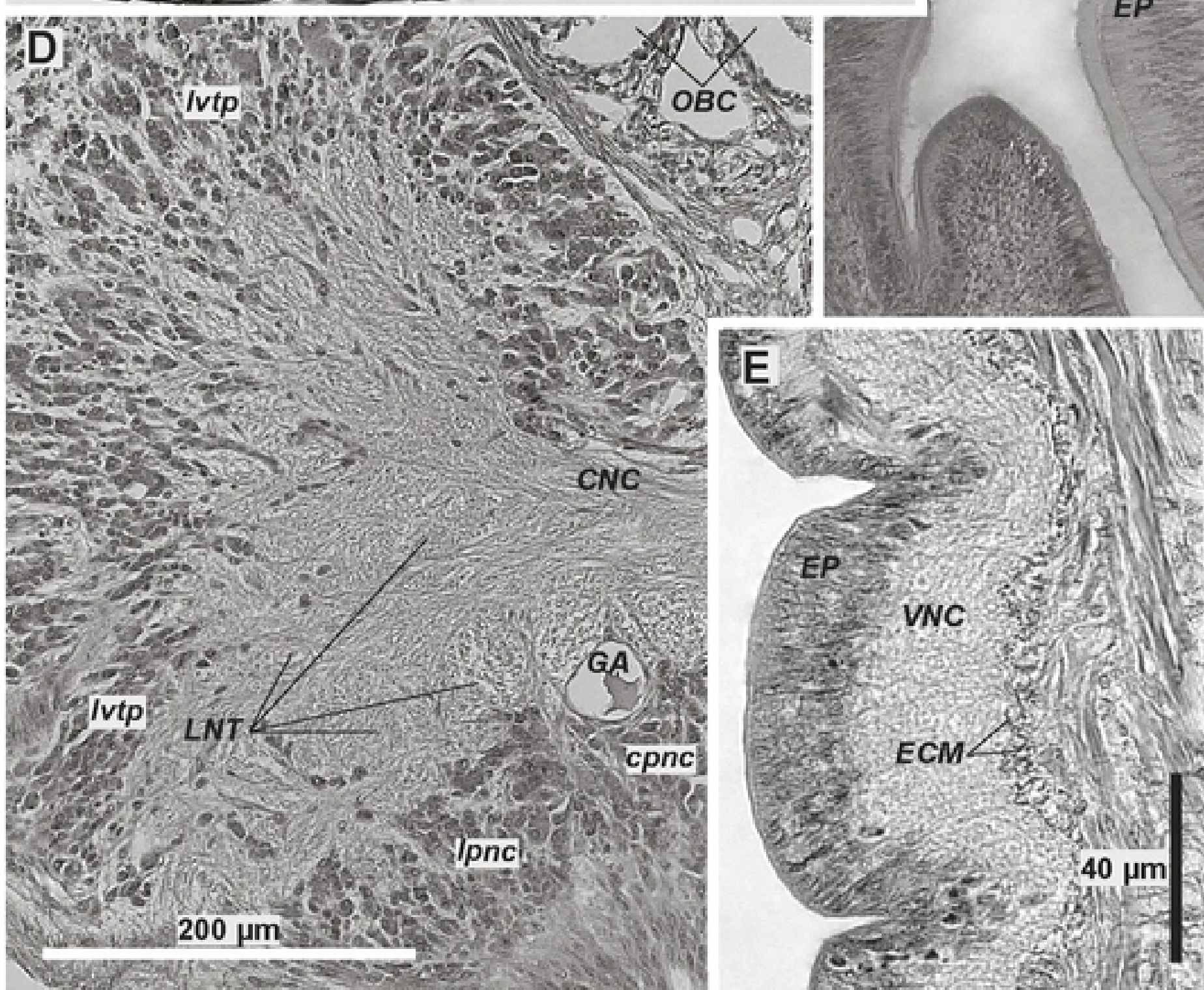

cpnc

EP
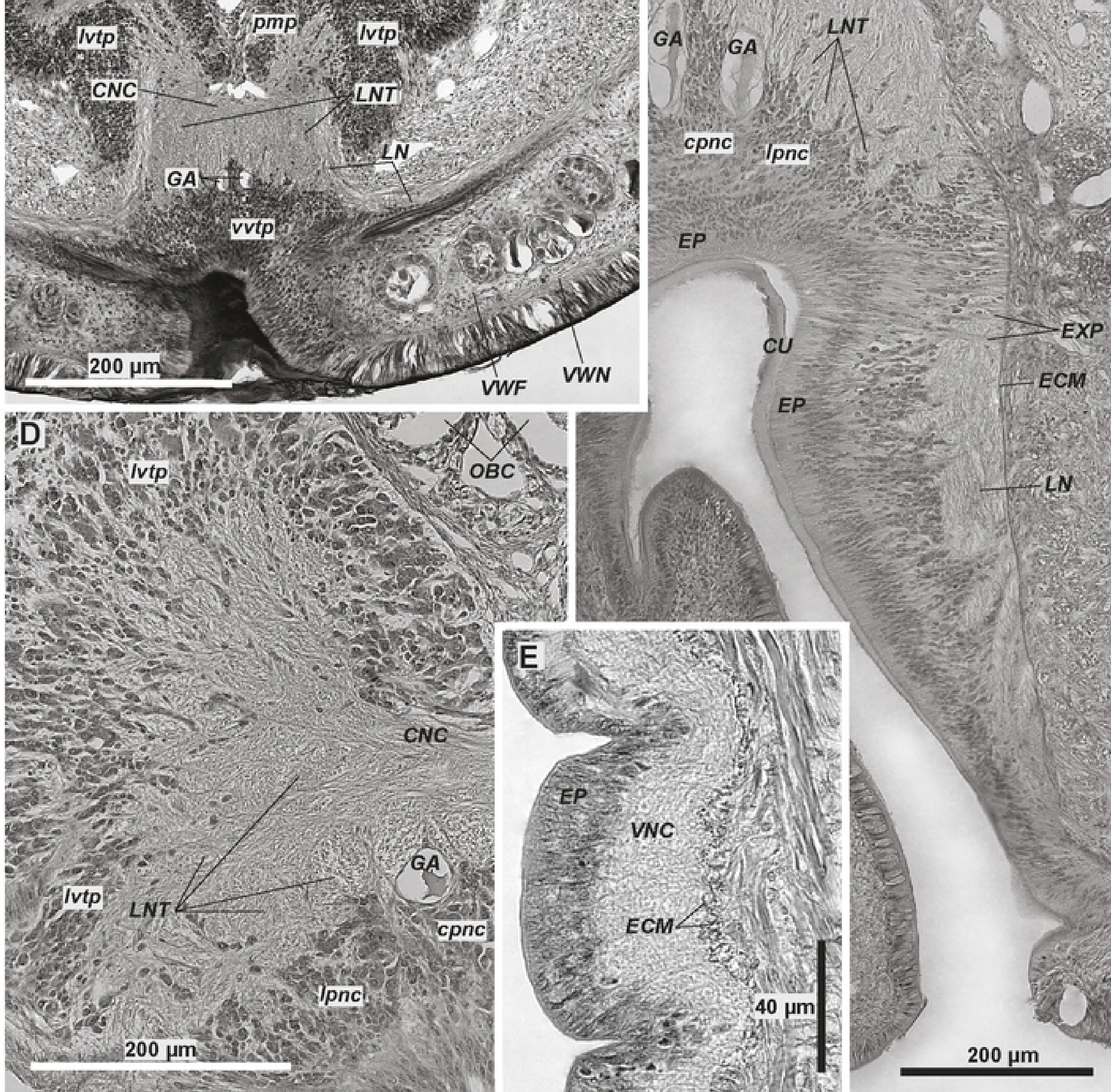

LN

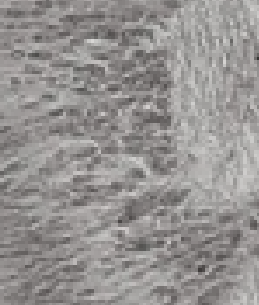

(x)

$O P$ ren -

$200 \mu \mathrm{m}$ 


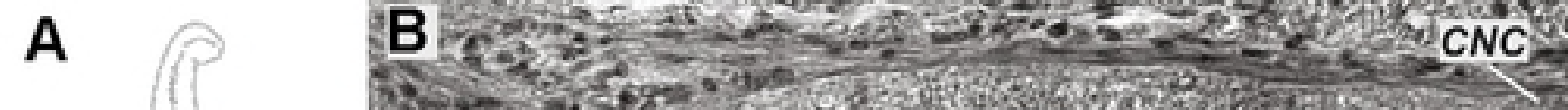

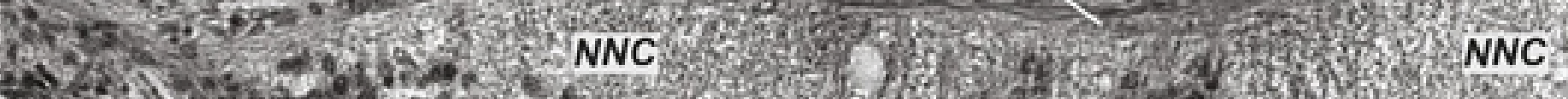

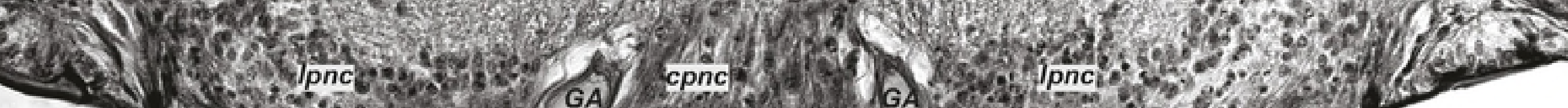

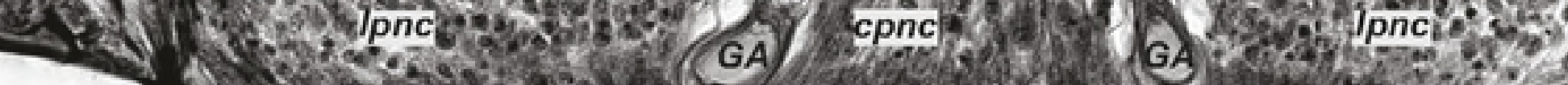

$100 \mu \mathrm{m}$ isos. 15 CU
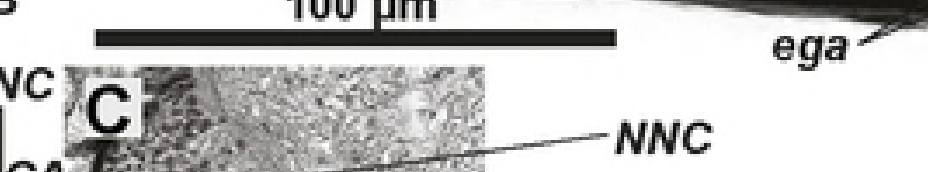

$G A$ $G A+1 p n c$ LN $L A$,

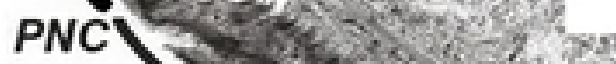

NC VNC
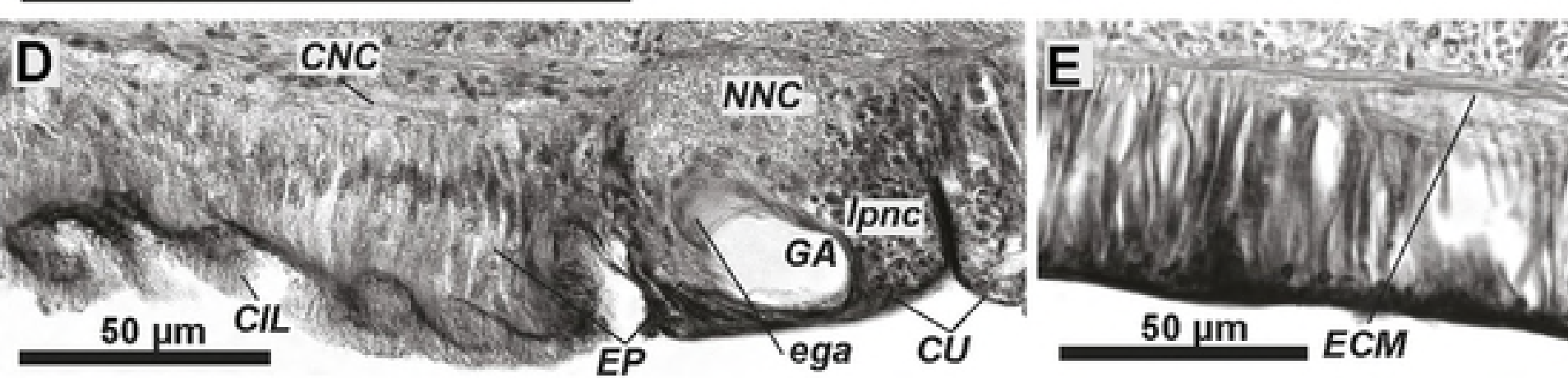
$50 \mu \mathrm{m}$
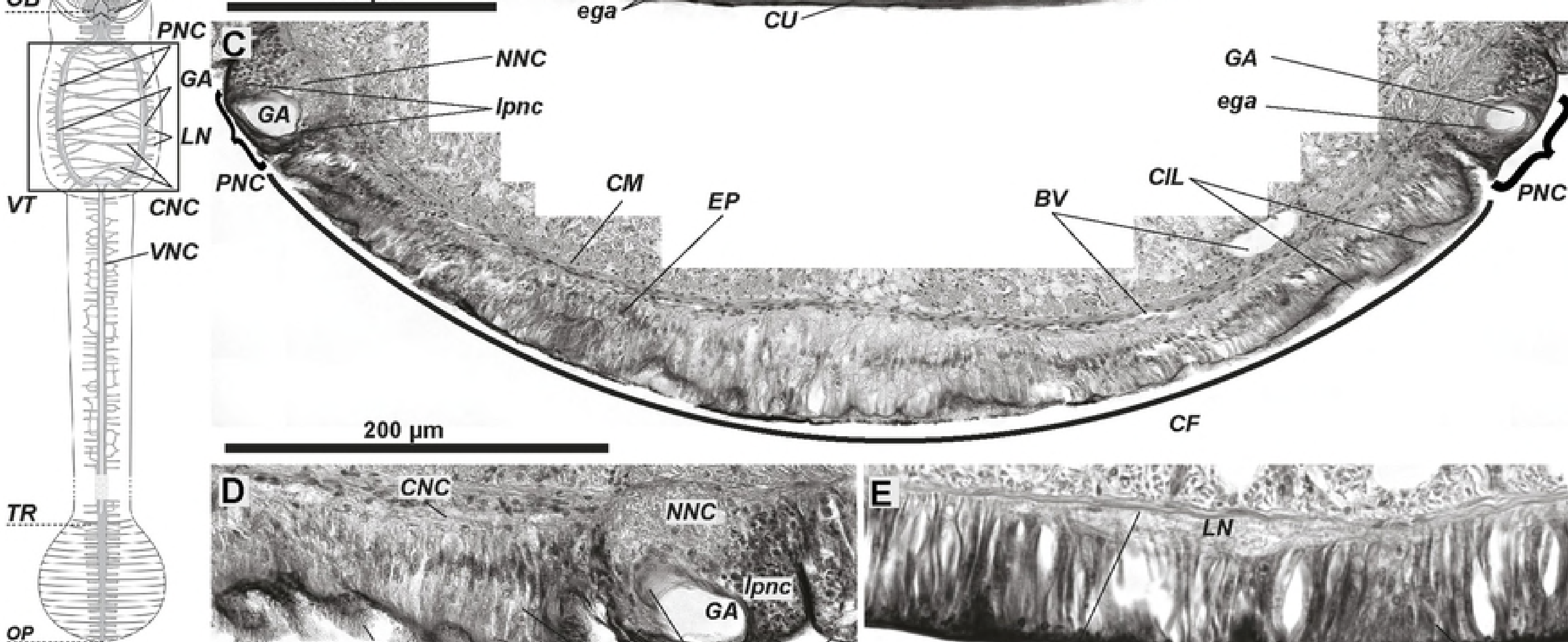
$\frac{4{ }^{2}}{2 N}$

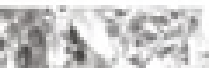
E.2. Irsen 
bioRxiv preprint doi: https://doi.org/10.1101/325431; this version posted MAy 4 G 2018 . The copyright holder for this preprint (which was

EXP

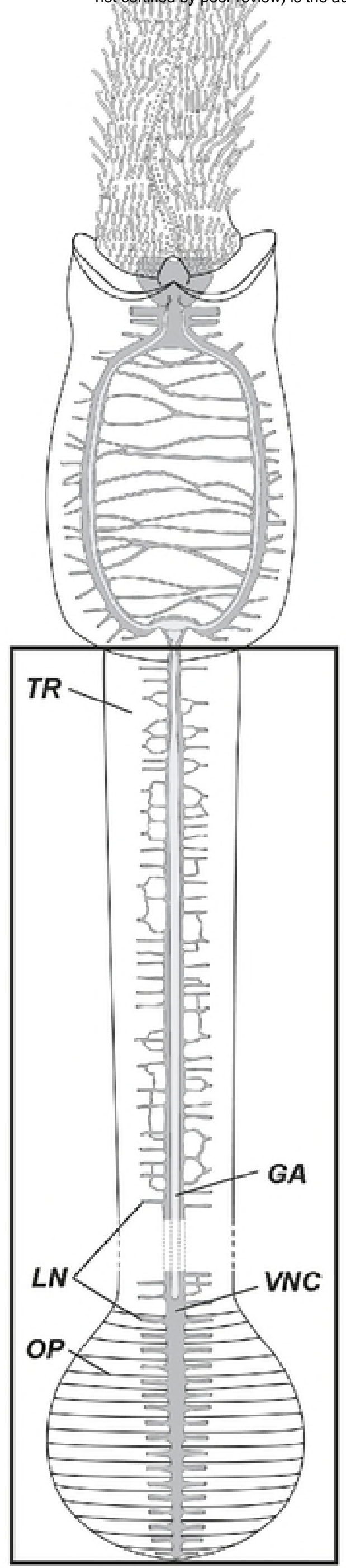
avilighlic wd

\section{$100 \mu \mathrm{m}$}

GA

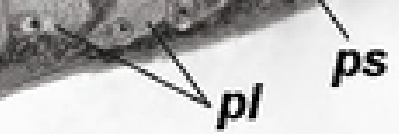

C FMV CM ËCM

NE $M E$ STM

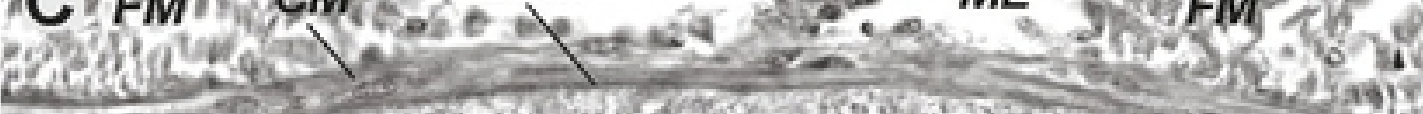

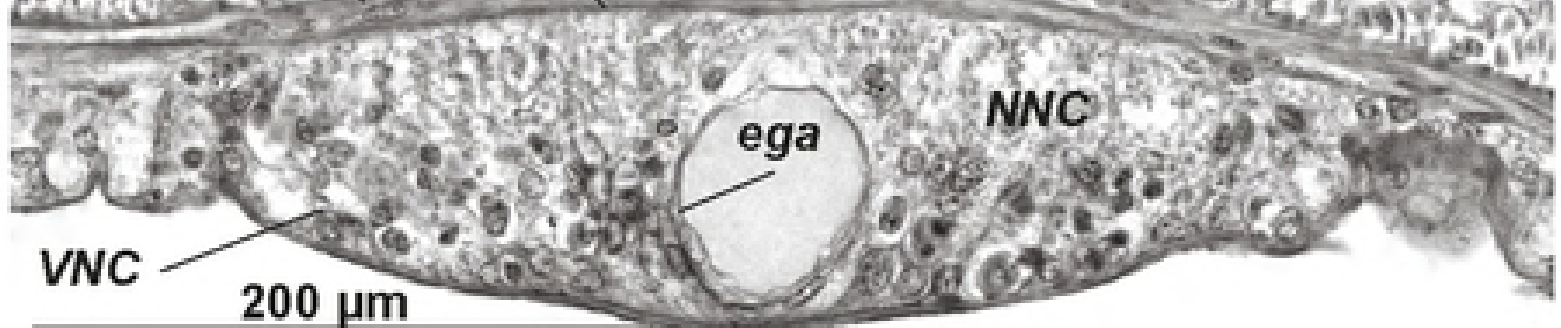

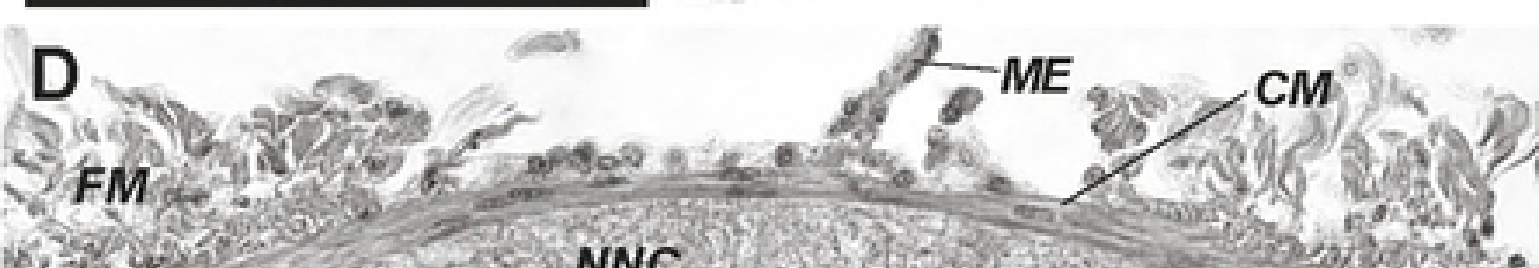

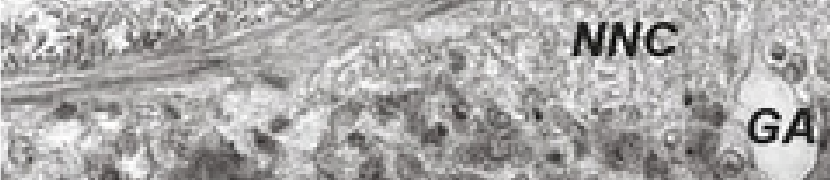

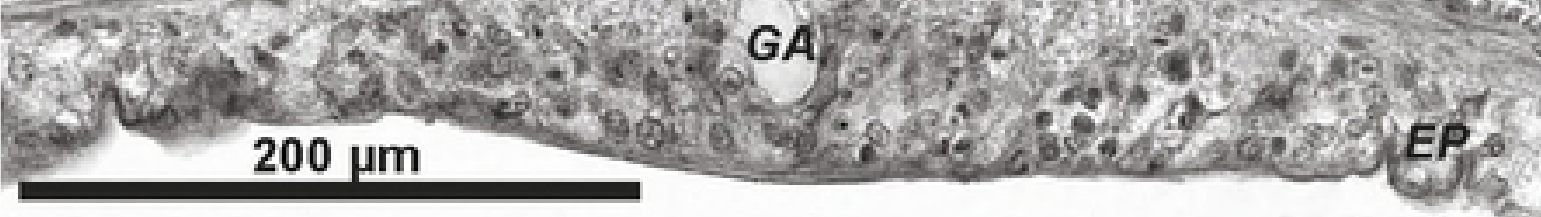

$1 \mathrm{~mm}$
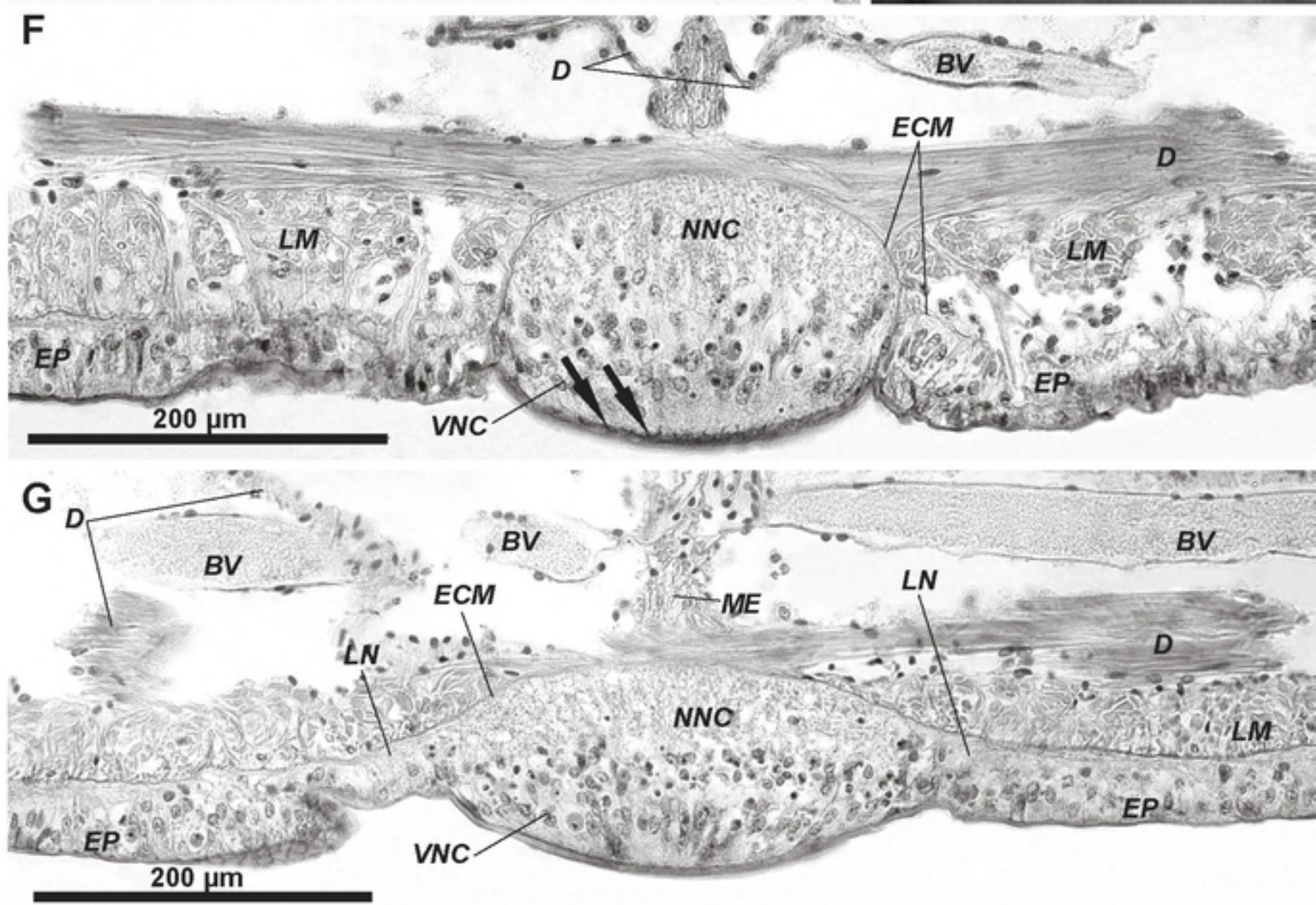


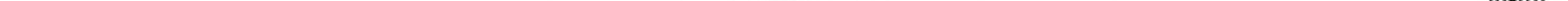




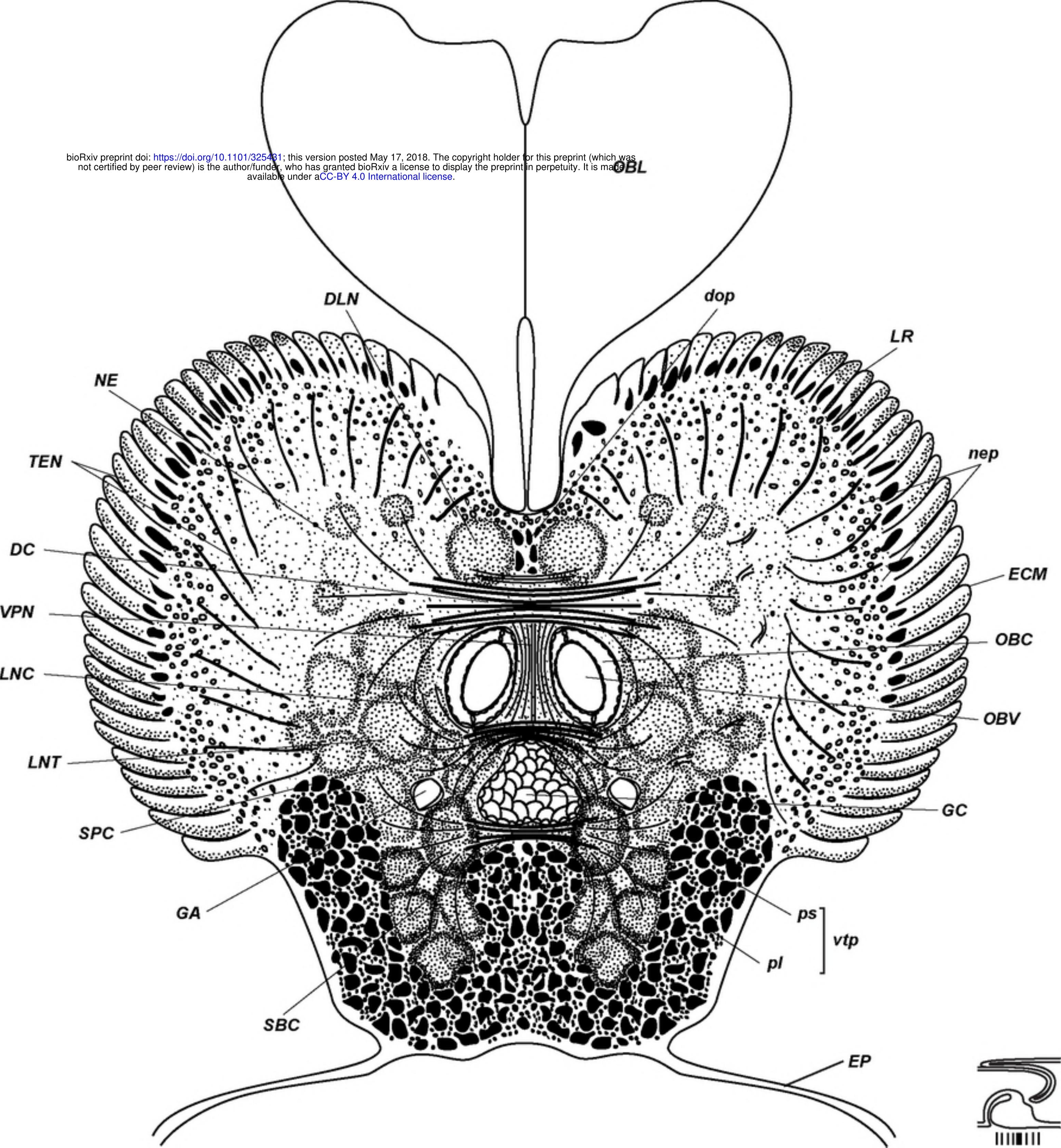


A

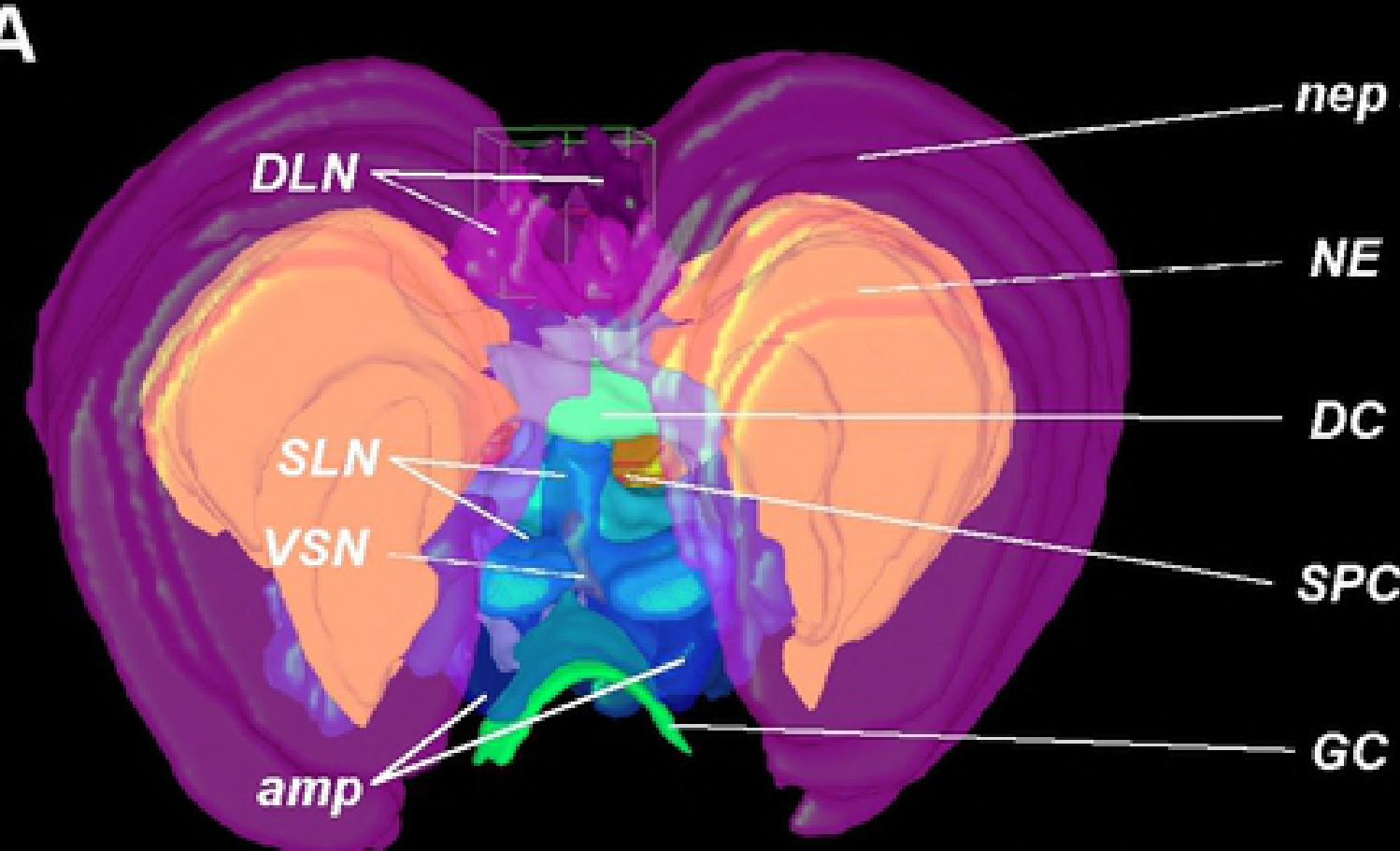

front
B

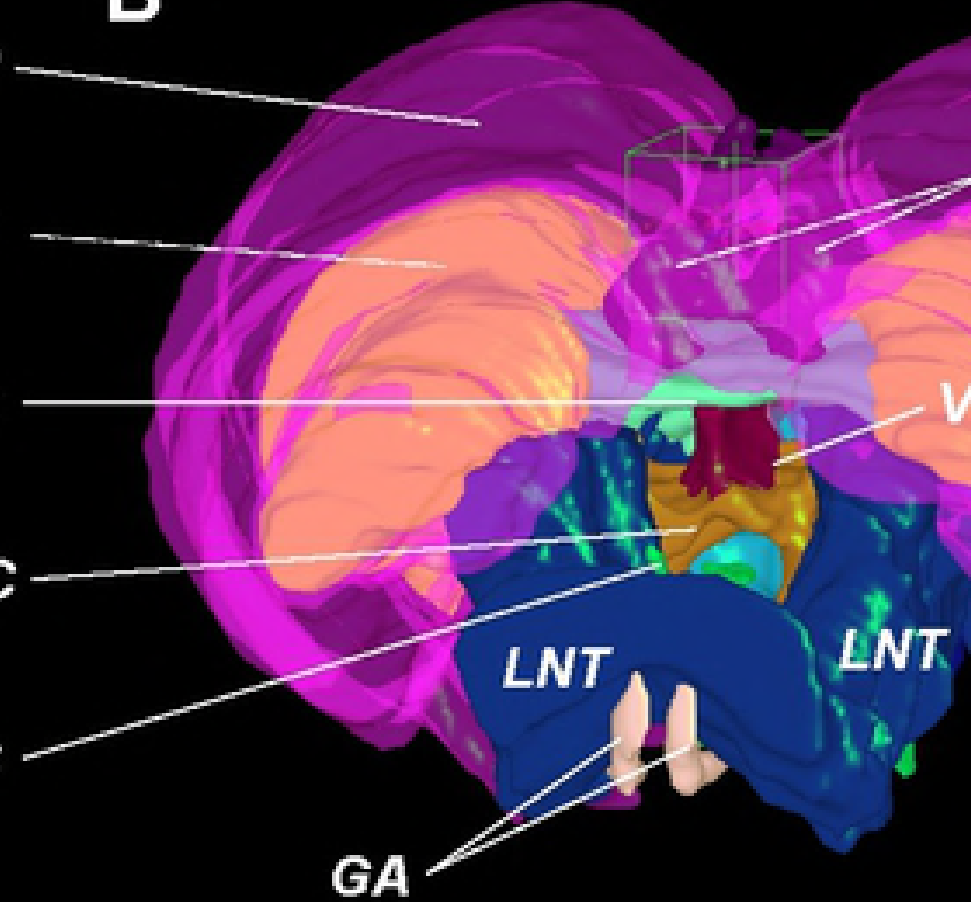

DLN

PN

C

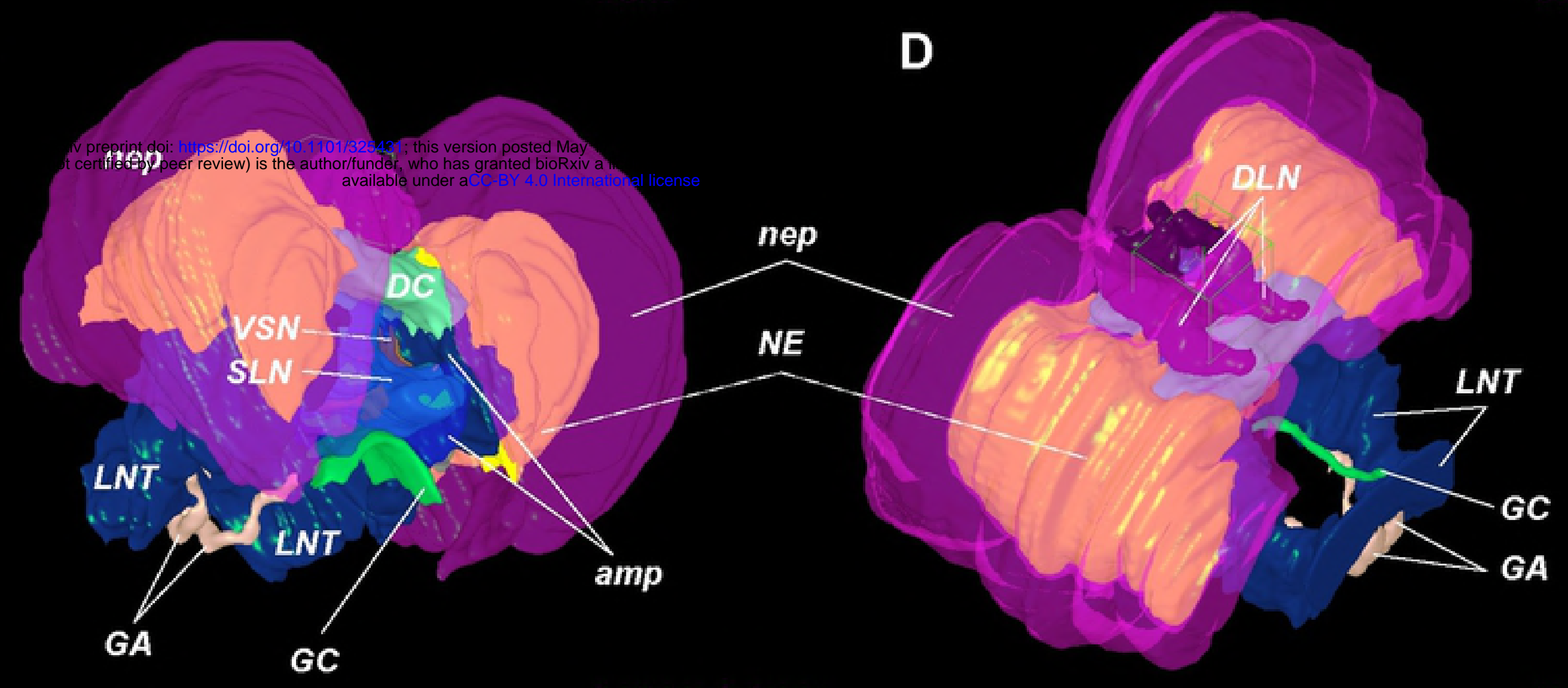

E

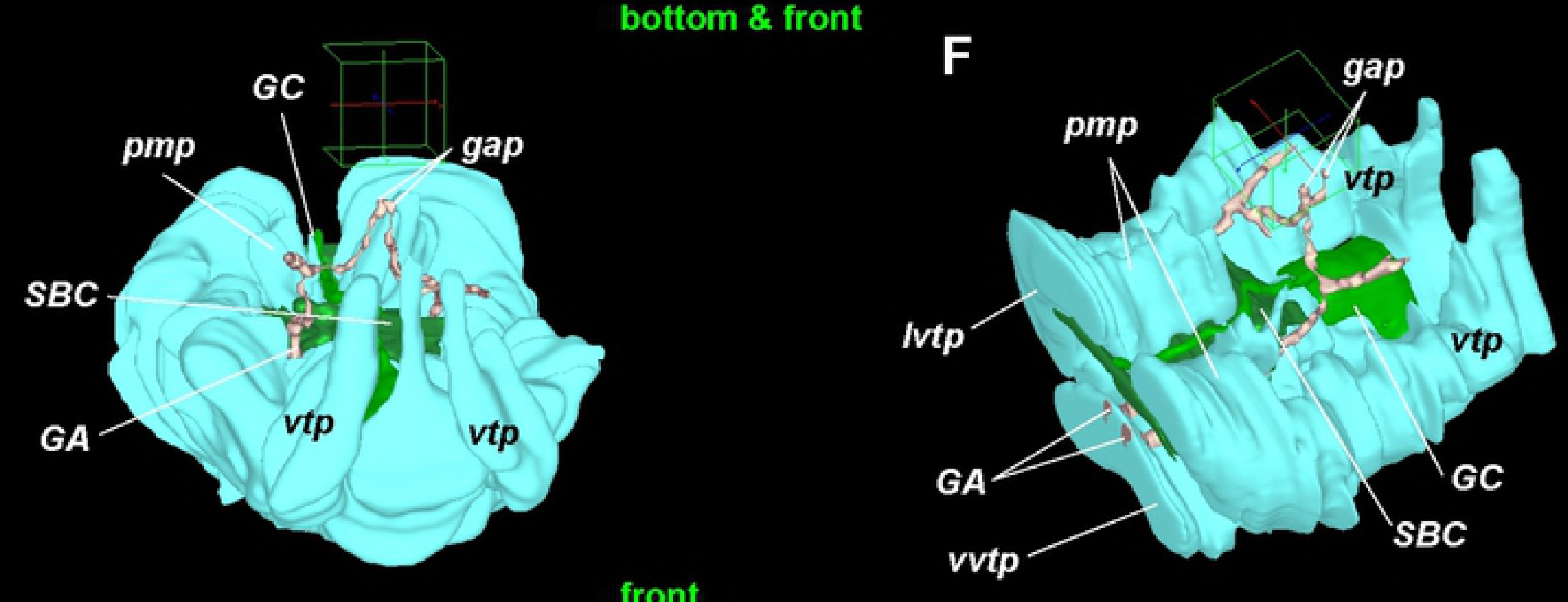

top \& back

C
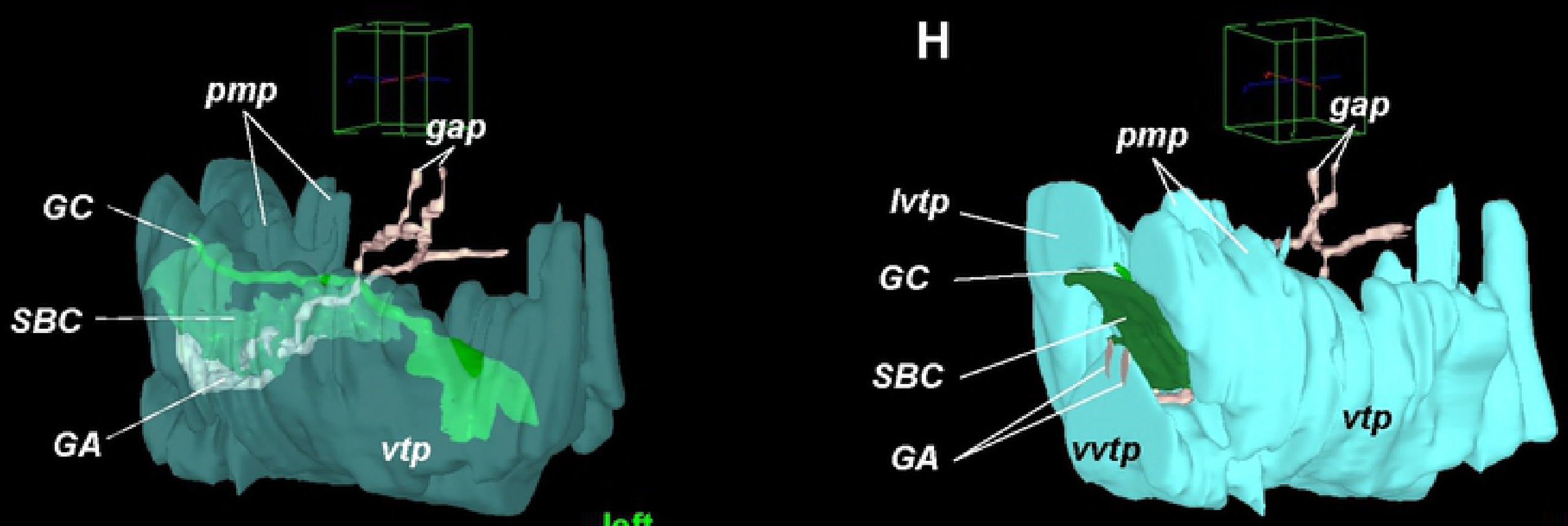
A

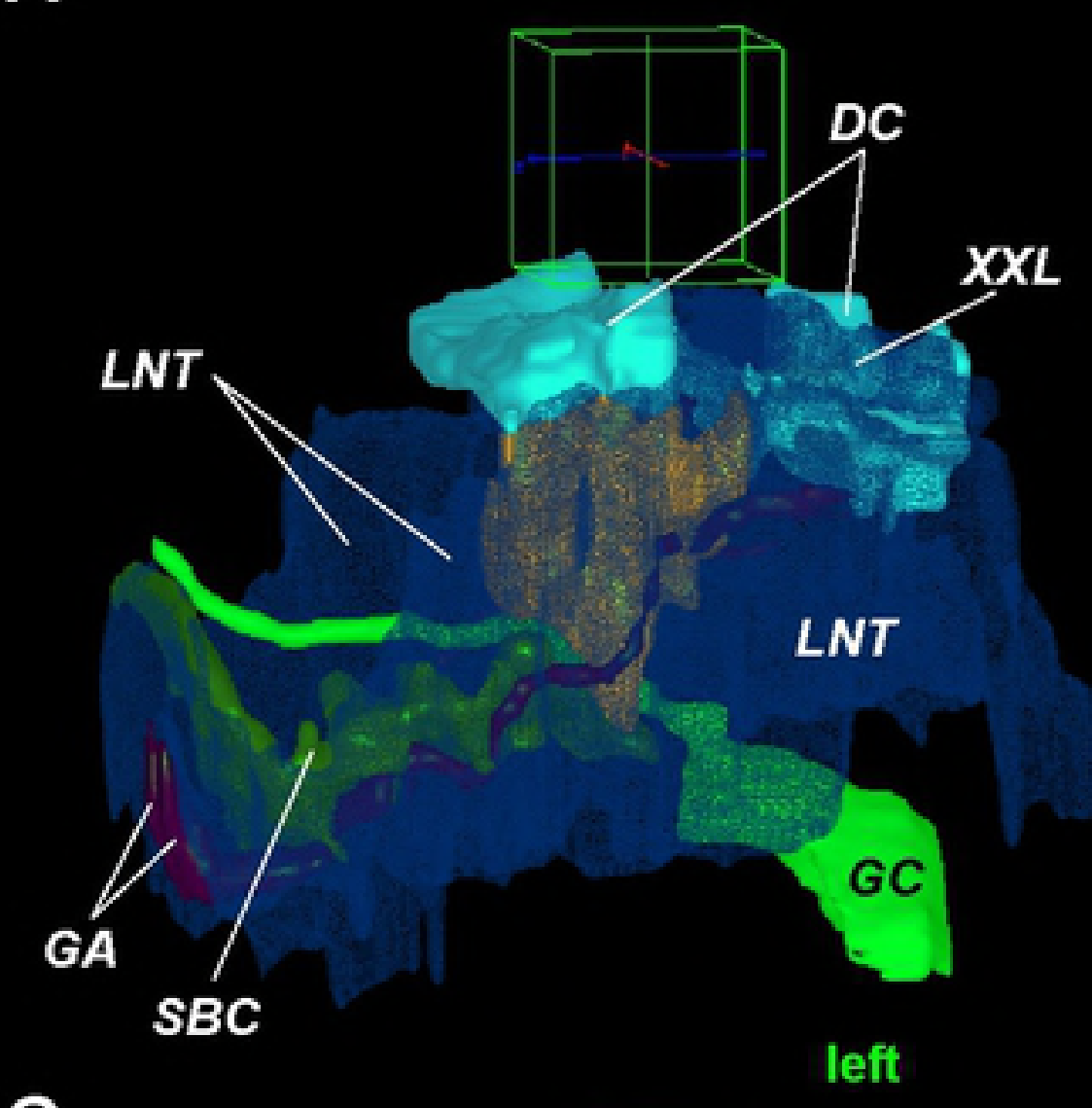

C

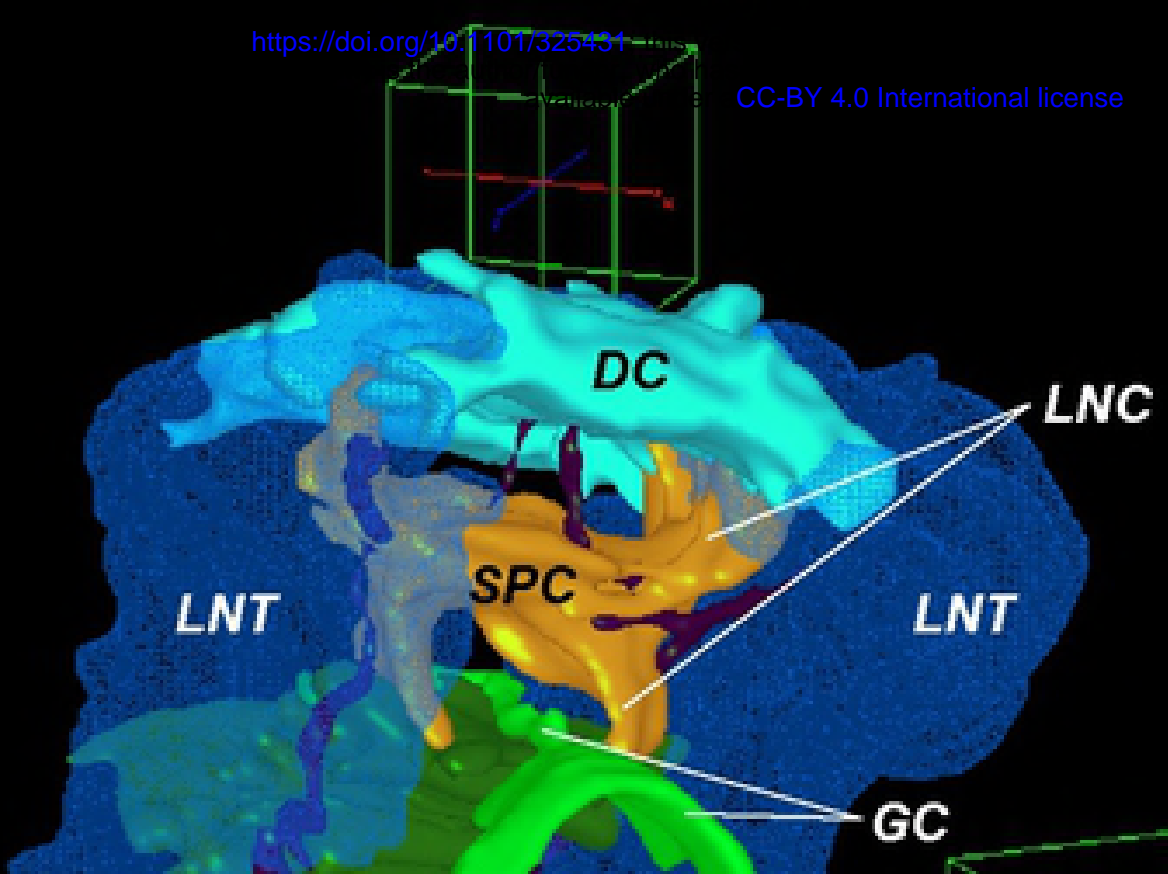

D

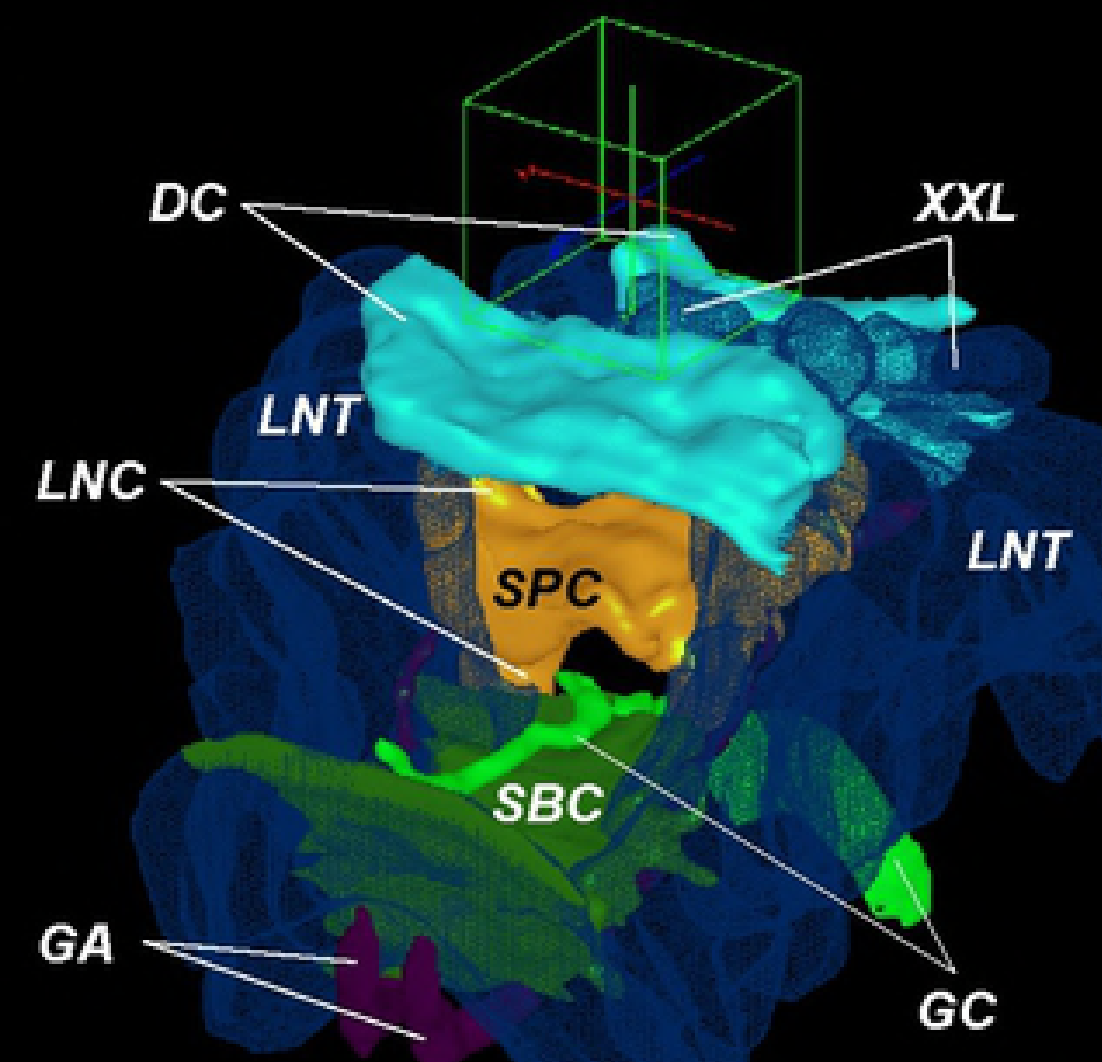
top \& back

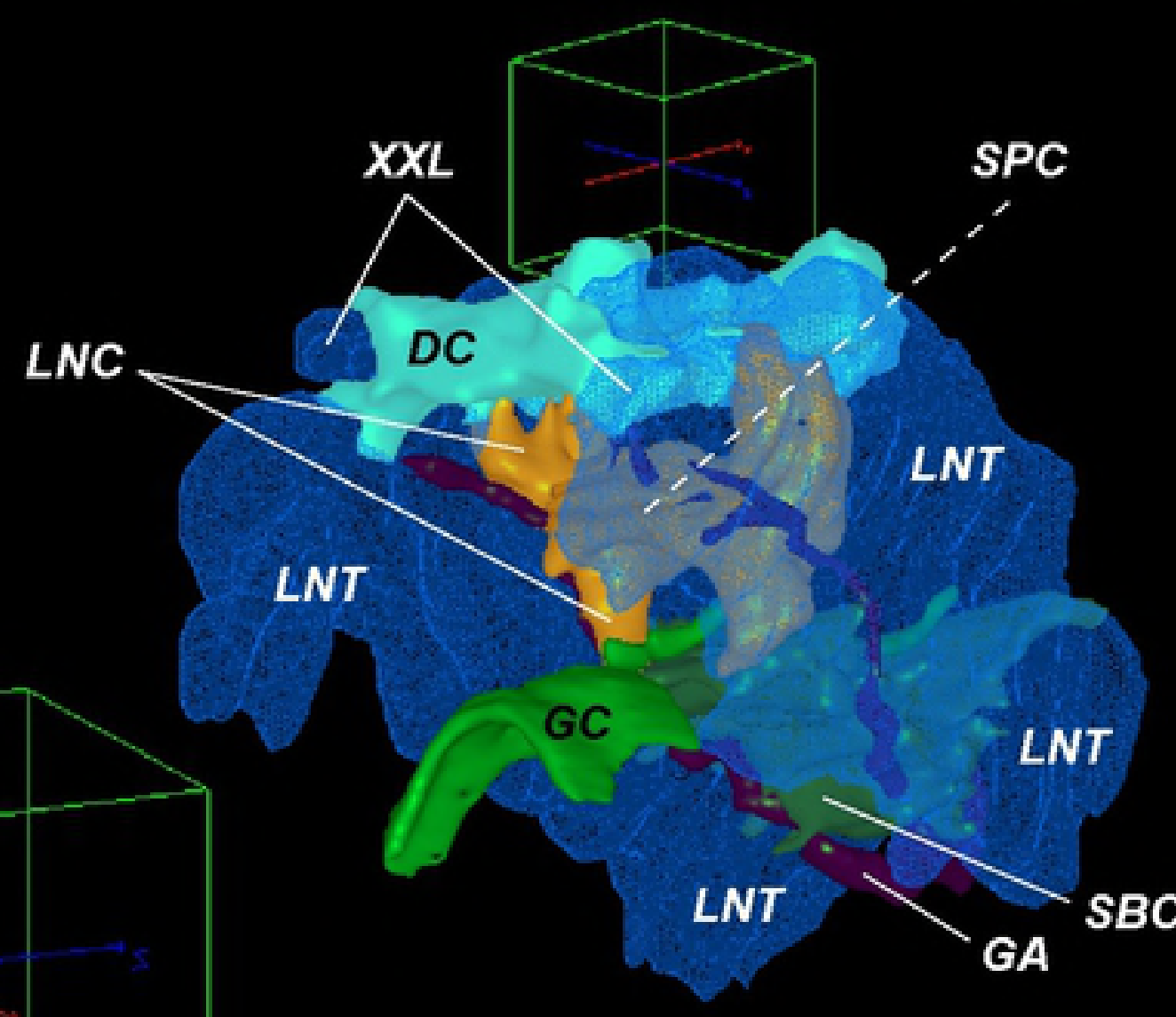
right \& bottom
E

bottom \& front

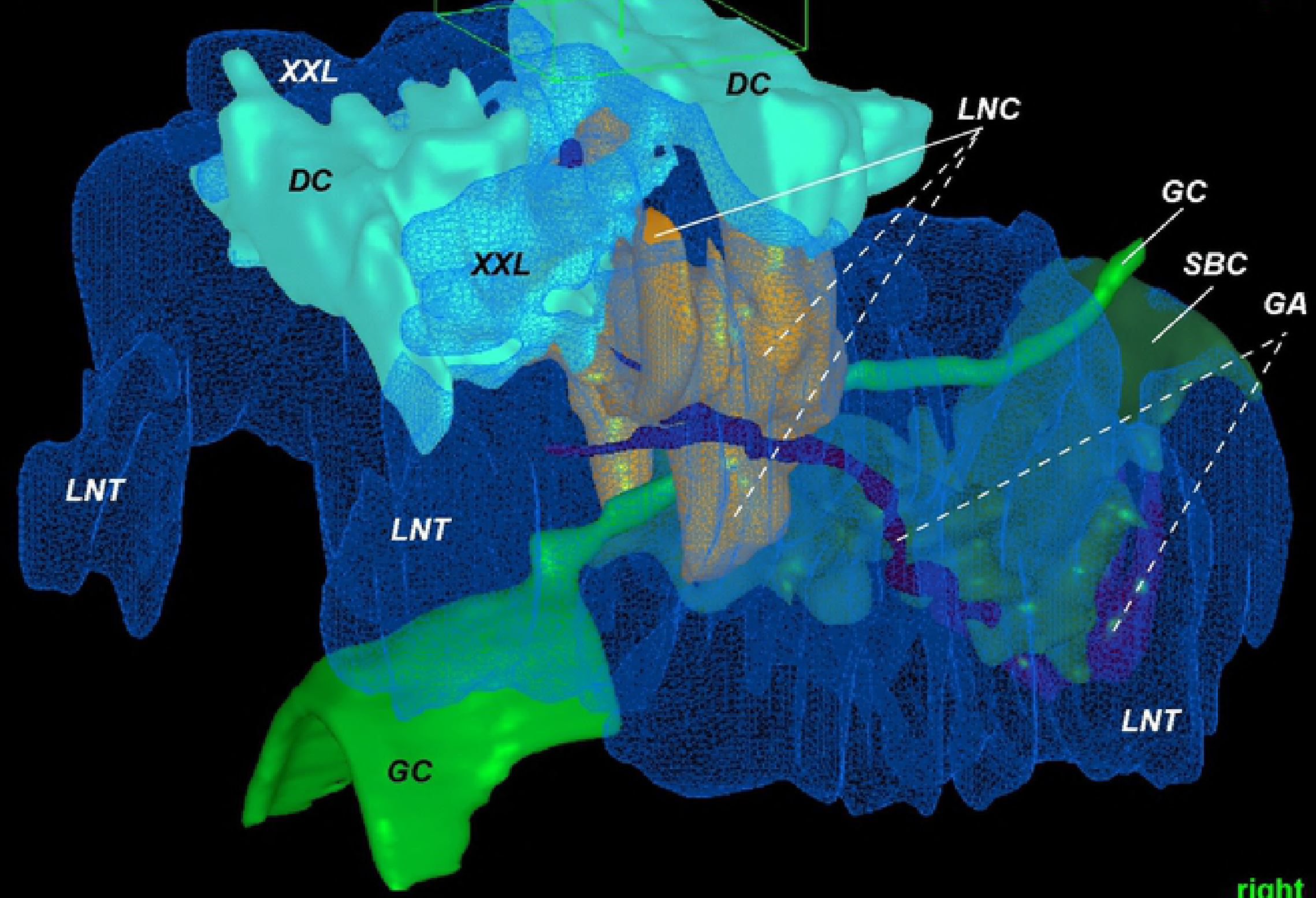



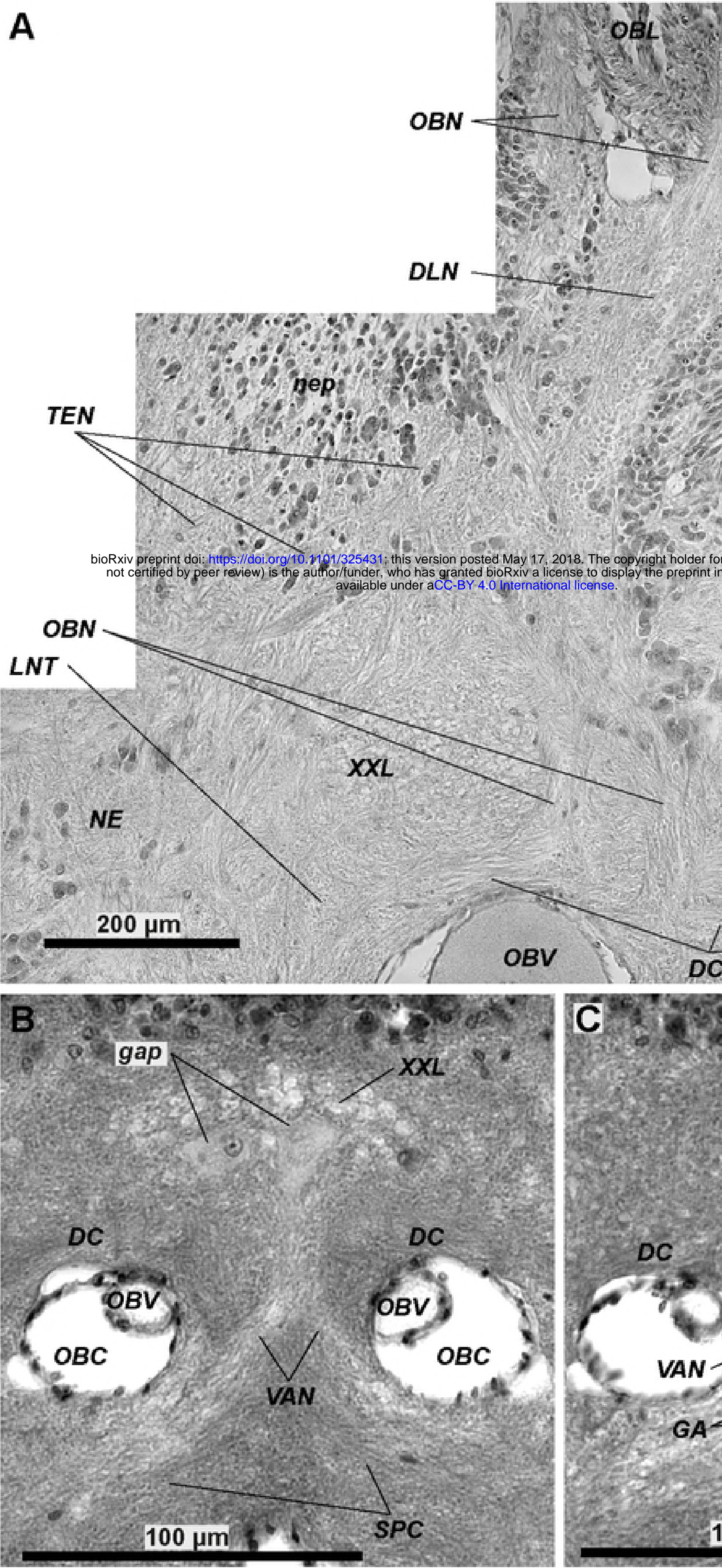

F
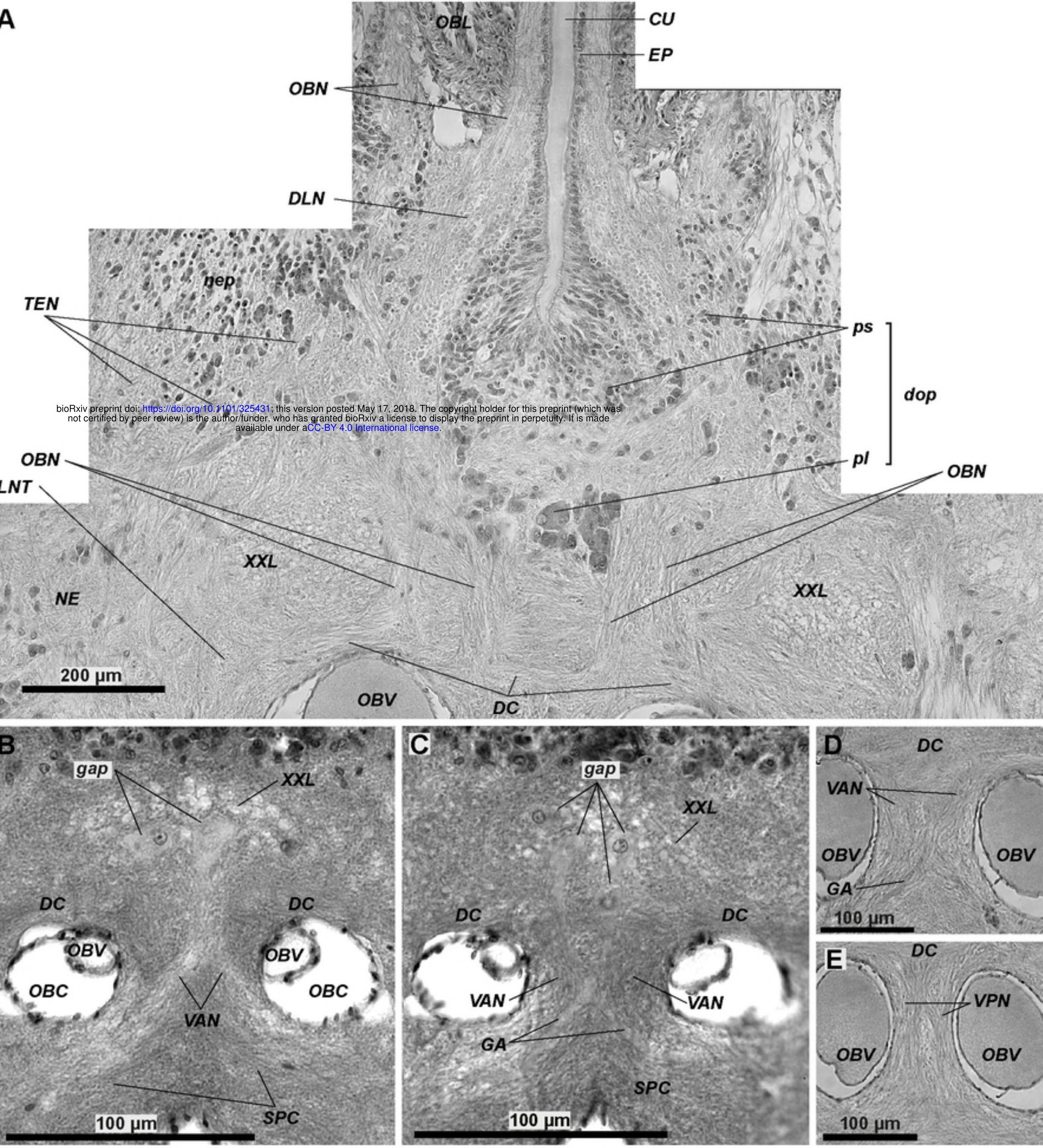


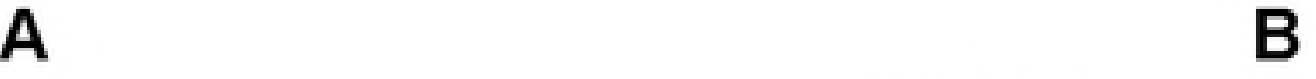

C

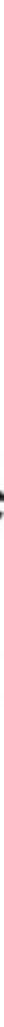


(N)
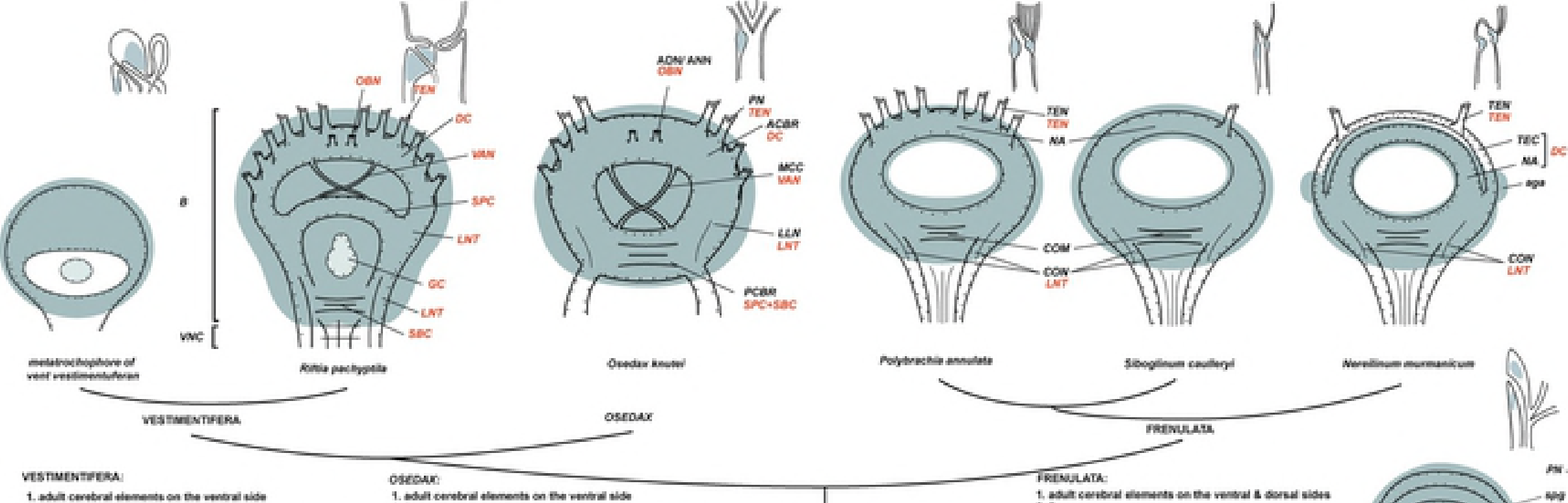

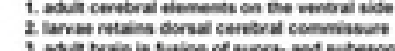

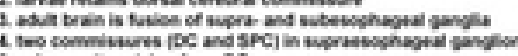

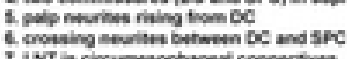

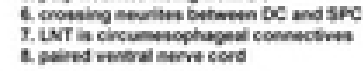

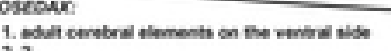

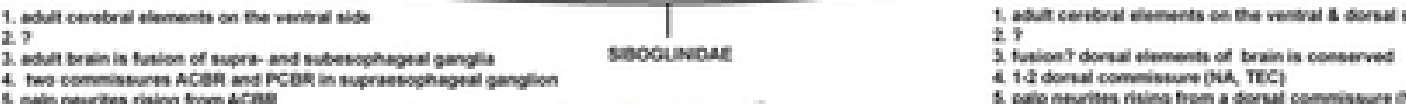

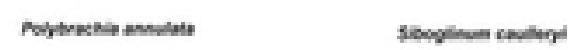
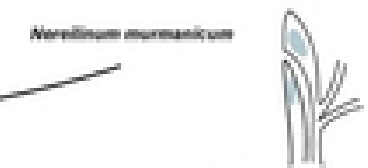

WVI

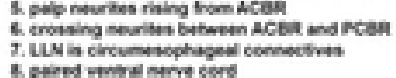
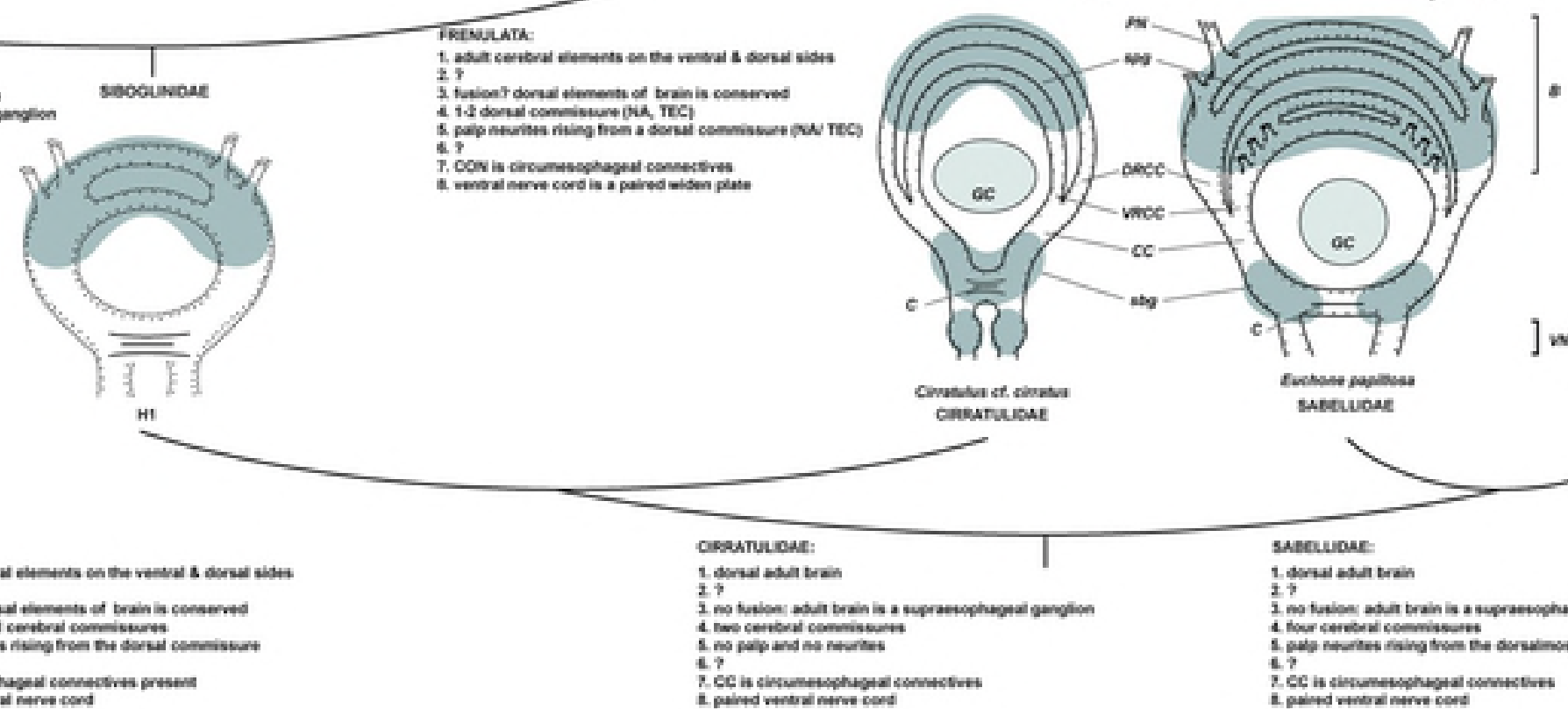

] $w$

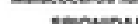

nt:

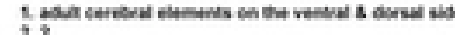

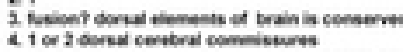

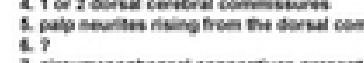

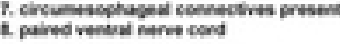

cosentricas:

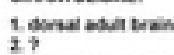

27 Nivion mol trensis

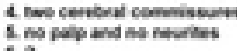

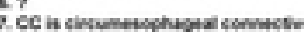

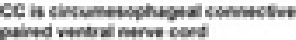

saeenour:

19mat wat trath

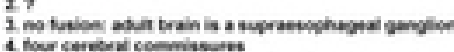

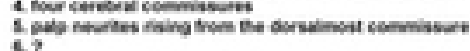

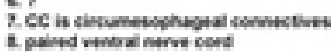

